\title{
Spontaneous and evolutionary changes in the antibiotic resistance of Burkholderia cenocepacia observed by global gene expression analysis
}

\author{
Andrea Sass ${ }^{1}$, Angela Marchbank', Elizabeth Tullis², John J LiPuma ${ }^{3}$ and Eshwar Mahenthiralingam*
}

\begin{abstract}
Background: Burkholderia cenocepacia is a member of the Burkholderia cepacia complex group of bacteria that cause infections in individuals with cystic fibrosis. B. cenocepacia isolate J2315 has been genome sequenced and is representative of a virulent, epidemic CF strain (ET12). Its genome encodes multiple antimicrobial resistance pathways and it is not known which of these is important for intrinsic or spontaneous resistance. To map these pathways, transcriptomic analysis was performed on: (i) strain J2315 exposed to sub-inhibitory concentrations of antibiotics and the antibiotic potentiator chlorpromazine, and (ii) on spontaneous mutants derived from J2315 and with increased resistance to the antibiotics amikacin, meropenem and trimethoprim-sulfamethoxazole. Two pan-resistant ET12 outbreak isolates recovered two decades after $\mathrm{J} 2315$ were also compared to identify naturally evolved gene expression changes.

Results: Spontaneous resistance in B. cenocepacia involved more gene expression changes and different subsets of genes than those provoked by exposure to sub inhibitory concentrations of each antibiotic. The phenotype and altered gene expression in the resistant mutants was also stable irrespective of the presence of the priming antibiotic. Both known and novel genes involved in efflux, antibiotic degradation/modification, membrane function, regulation and unknown functions were mapped. A novel role for the phenylacetic acid (PA) degradation pathway genes was identified in relation to spontaneous resistance to meropenem and glucose was found to repress their expression. Subsequently, $20 \mathrm{mM}$ glucose was found to produce greater that 2-fold reductions in the MIC of multiple antibiotics against B. cenocepacia J2315. Mutation of an RND multidrug efflux pump locus (BCAM0925-27) and squalene-hopene cyclase gene (BCAS0167), both upregulated after chlorpromazine exposure, confirmed their role in resistance. The recently isolated outbreak isolates had altered the expression of multiple genes which mirrored changes seen in the antibiotic resistant mutants, corroborating the strategy used to model resistance. Mutation of an $A B C$ transporter gene (BCAS0081) upregulated in both outbreak strains, confirmed its role in B. cenocepacia resistance.

Conclusions: Global mapping of the genetic pathways which mediate antibiotic resistance in $B$. cenocepacia has revealed that they are multifactorial, identified potential therapeutic targets and also demonstrated that putative catabolite repression of genes by glucose can improve antibiotic efficacy.
\end{abstract}

\section{Background}

Burkholderia cepacia complex (Bcc) bacteria are antibiotic resistant opportunistic pathogens known for their ability to infect individuals with cystic fibrosis (CF). The complex currently consists of 17 formally named species, of which B. multivorans and B. cenocepacia most often cause infection in CF [1]. The B. cenocepacia ET12 strain is one of

\footnotetext{
* Correspondence: MahenthiralingamE@cardiff.ac.uk

'Organisms and Environment Division, Cardiff School of Biosciences, Cardiff

University, Main Building, Park Place, Cardiff, Wales, CF10 3AT, UK

Full list of author information is available at the end of the article
}

the most problematic Bcc strains infecting patients with CF. It was most likely recognised as early as 1984 in the pioneering studies of Isles et al. [2] that showed that "P. cepacia" could cause an invasive, frequently fatal infection that became known "cepacia syndrome." Subsequent studies demonstrated that ET12 strains could transmit between CF patients by social contact [3], had spread intercontinentally across North America and Europe, and could replace infection with other Bcc species (reviewed [4]). Isolates of the ET12 strain can be identified using a number of characteristics including presence of the cable
C Biomed Central

() 2011 Sass et al; licensee BioMed Central Ltd. This is an Open Access article distributed under the terms of the Creative Commons Attribution License (http://creativecommons.org/licenses/by/2.0), which permits unrestricted use, distribution, and reproduction in any medium, provided the original work is properly cited. 
pilus gene and the Burkholderia cepacia epidemic strain marker, a RAPD 02 genotype fingerprint, a $r e c A$ subgroup III-A phylotype (reviewed [5]), and most recently as possessing the multilocus sequence type (MLST) ST-28 [6]. As a result of the devastating CF infections caused by the B. cenocepacia ET12 strain, it has become one of the most studied Bcc bacteria in terms of virulence [7] and antimicrobial resistance $[8,9]$.

The B. cenocepacia ET12 isolate, J2315, was recovered from an infected CF patient in Edinburgh, UK, in 1989 [3] and has been subject to complete genome sequence analysis [6]. This genomic resource enabled a B. cenocepacia microarray to be designed that has greatly enhanced our molecular understanding of this CF pathogen $[10,11]$. B. cenocepacia encodes multiple pathways that it uses to resist killing by antimicrobial agents, including efflux pumps [12], lipopolysaccharide, beta-lactamases and a trimethoprim resistant dihydrofolate reductase enzyme [6]. A problematic feature of chronic Bcc infection in CF is the ability of the infecting strain to adapt to very high levels of antibiotic resistance. The emergence of pan resistant Bcc strains, which are either untreatable or require combinations of multiple antibiotics to suppress exacerbations of infection, is of great concern [8]. The molecular mechanisms behind the evolution of spontaneous antimicrobial resistance in B. cenocepacia are not known and how the multiple resistance pathways function on a global scale to allow $B$. cenocepacia to survive antibiotic therapy is poorly understood. Cationic drugs such as chlorpromazine and theophylline have been shown to reduce the minimal inhibition concentration (MIC) of certain antibiotics that are otherwise ineffective against Bcc bacteria [13] and a more complete understanding of how these non-antibiotic drugs act may also provide novel therapies.

In this study, we employed a transcriptomic, microarraybased strategy to investigate the following (Figure 1): (i) how exposure to sub-inhibitory concentrations of three antibiotics (amikacin, meropenem and trimethoprim-sulfamethoxazole) that are widely used to treat CF infections [14] and sub-inhibitory exposure to the cationic drug chlorpromazine affect gene expression in B. cenocepacia, (ii) how B. cenocepacia alters gene expression after the selection of spontaneous resistant mutants by the three latter antibiotics, and finally, (iii) how the antimicrobial resistance characteristics and global gene expression of the strain have naturally evolved during the 19 years it has circulated within the CF community since the isolation of the genome sequenced isolate, B. cenocepacia J2315 in 1989.

\section{Results and discussion}

Antibiotic susceptibility of B. cenocepacia J2315 and derived mutants with spontaneous resistance

Using the clinically defined MIC breakpoints, wild type B. cenocepacia J2315 was resistant to 15 of the 17 antibiotics tested; susceptibility to meropenem and ceftazidime was classified as intermediate (Table 1). Synergy testing indicated no synergy in any of the combination of two antibiotics tested against J2315. The antibiotic potentiator chlorpromazine reduced the MIC of amikacin (200 to $100 \mathrm{mg} / \mathrm{L}$ ), tobramycin (150 to 50 $\mathrm{mg} / \mathrm{L}$ ) and azithromycin (50 to $15 \mathrm{mg} / \mathrm{L}$ ) at a concentration of $0.2 \mathrm{mM}$; the same concentration of prochlorperazine produced slightly greater reductions in antibiotic MIC (amikacin to 20, tobramycin to 20 and azithromycin to $10 \mathrm{mg} / \mathrm{L}$ ). These reductions were consistent with previous data obtained for "B. cepacia" strain ATCC 13945 [13] which is a B. cenocepacia IIIA strain, but not from the ET12 lineage (see http://pubmlst.org/bcc. As theophylline was not found to alter the susceptibility of strain J2315, chlorpromazine in combination with amikacin was selected as the optimal potentiator-antibiotic combination to examine from the $B$. cenocepacia global gene expression perspective because it had a good additive effect, did not present solubility problems in growth medium as seen with prochlorperazine, and allowed reproducible growth curves to be obtained for strain $\mathrm{J} 2315$.

Spontaneous mutants with elevated resistance to amikacin (J2315-A), meropenem (J2315-M) and trimethoprim-sulfamethoxazole (J2315-T) were generated by plating on selective agar containing each respective antibiotic (see Methods). The mutants had MICs that were increased over the wild type, 2.3-, 2.1- and 5-fold, for each respective antibiotic (Table 1). The growth rate of each mutant was unaltered in comparison to J2315 and the resistant phenotype of each mutant was stable after 15 transfers on agar without antibiotics. The spontaneous mutants appeared at a frequency of $18.1( \pm 7.9) \times$ $10^{-7}$ for amikacin, $4.5( \pm 0.5) \times 10^{-7}$ for meropenem, and 14.4 $( \pm 4.1) \times 10^{-8}$ for trimethoprim-sulfamethoxazole; no difference in mutation frequency was observed between 2315 cultures that were plated in log phase or at the beginning of stationary phase. Mutant J2315-A showed an increased resistance to all other aminoglycosides tested, and interestingly also to the beta-lactams meropenem, ceftazidime, cefotaxime and aztreonam (Table 1). The meropenem-resistant mutant, J2315-M, demonstrated elevated resistance to all beta-lactams tested, as well as increases in tobramycin, chlorampheni$\mathrm{col}$ and tetracycline resistance. Mutant J2315-T was more resistant to fluoroquinolones, chloramphenicol, rifampicin and tetracycline (Table 1).

\section{Antibiotic susceptibility and features of clonal outbreak strains circulating 19 years after isolation of $\mathrm{B}$. cenocepacia $\mathrm{J} 2315$}

Two isolates from two CF patients involved in a recent ET12 outbreak [15], BCC1616 and BCC1617, were 


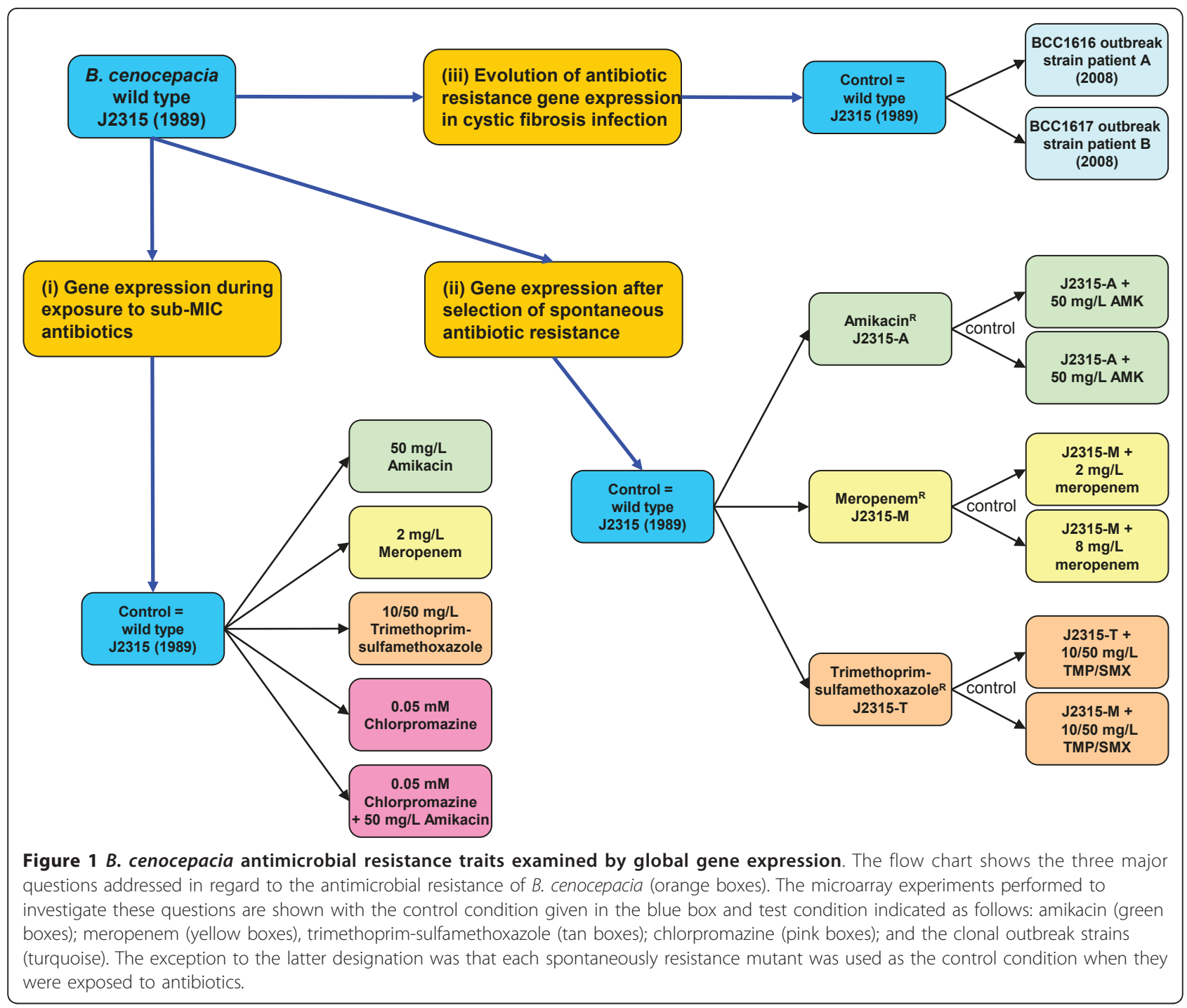

compared to J2315 in terms of phenotype and global gene expression genotype. They represent the natural evolution of this epidemic strain as an infectious agent circulating in CF community since the recovery of J2315 in 1989. BCC1616 and BCC1617 were both found to be clonally identical with J2315 (MLST ST-28). Each was more resistant to aminoglycosides, macrolides, fluoroquinolones and tetracycline, than J2315 (Table 1); BCC1616 was less susceptible to all beta-lactams tested. This is in concordance with previous observations of rapid evolution of elevated drug resistance within sequential ET12 CF isolates, where isolates from episodes of clinical exacerbation were more resistant than those recovered during stable clinical conditions [9].

The growth rate of BCC1616 and BCC1617 on Iso-sensitest broth (doubling time $=3.0$ and 2.4 hours, respectively) was also slower than $\mathrm{J} 2315$ (doubling time $=1.8$ hours). $P$. aeruginosa isolates recovered from CF infection have reduced growth rates compared to those from other sources [16] and a slower growth rate is also linked to increased antibiotic resistance in bacterial pathogens [17]. Both of the recent ET12 clones were not motile in contrast to J2315 (Additional file 1, Figure S1). Loss of motility has been observed among $P$. aeruginosa isolates recovered from chronic CF infection [18]. Both J2315 and BCC1616 were auxotrophic for tyrosine and phenylalanine. Auxotrophy for amino acids has also been observed in CF isolates of $P$. aeruginosa and B. cepacia [19] and is attributed to the CF lung environment being rich in amino acids and other nutrients, selecting for auxotrophic variants. J2315 and BCC1616 both formed a brown pigment at the beginning of stationary phase on Iso-sensitest and on LB medium. $P$. aeruginosa $\mathrm{CF}$ isolates often produce a brown, melanin-like pigment, attributed to accumulation of homogentisate in the growth medium [16]. The same phenomenon has been observed for B. cenocepacia [20] with 
Table 1 Antibiotic susceptibility (mg/L) of B. cenocepacia J2315, resistant mutants and outbreak isolates

\begin{tabular}{|c|c|c|c|c|c|c|c|}
\hline Antibiotic clasBs & Antibiotic name & $\begin{array}{c}\text { wild type } \\
\text { J2315 }\end{array}$ & $\begin{array}{c}\text { J2315-A } \\
\left(\text { (AMKr) }^{r}\right.\end{array}$ & $\begin{array}{c}\begin{array}{c}\text { J2315-M } \\
\left(M^{\prime} R^{r}\right)\end{array} \\
\end{array}$ & $\begin{array}{c}\mathrm{J} 2315-\mathrm{T} \\
\left(\mathrm{TMP}{ }^{\mathrm{r}}\right)\end{array}$ & $\begin{array}{c}\text { BCC } \\
1616 \\
\end{array}$ & $\begin{array}{c}\text { BCC } \\
1617 \\
\end{array}$ \\
\hline \multirow[t]{6}{*}{ Beta-lactams } & Meropenem & 7 & 13 & 15 & 6 & 30 & 7 \\
\hline & Imipenem & 125 & 125 & 175 & 100 & 175 & 100 \\
\hline & Ceftazidime & 10 & 30 & 40 & 10 & 60 & 5 \\
\hline & Cefotaxime & 250 & 500 & 1200 & 250 & $>1500$ & 15 \\
\hline & Aztreonam & 250 & 500 & 1500 & 200 & $>1500$ & 40 \\
\hline & Piperacillin & 450 & 450 & 900 & 350 & 1500 & 40 \\
\hline \multirow[t]{3}{*}{ Aminoglycosides } & Amikacin & 200 & 450 & 200 & 200 & 450 & 900 \\
\hline & Gentamicin & 700 & 5000 & 450 & 400 & 10000 & $>10000$ \\
\hline & Tobramycin & 150 & 500 & 300 & 125 & 1500 & 3000 \\
\hline \multirow[t]{2}{*}{ Macrolides } & Azithromycin & 50 & 40 & 40 & 30 & 200 & $>500$ \\
\hline & Erythromycin & 150 & 150 & 200 & 150 & 500 & 800 \\
\hline Folate synthesis inhibitors & Trimethoprim/Sulfamethoxazole & $30 / 150$ & $20 / 100$ & $30 / 150$ & $150 / 750$ & $10 / 50$ & $20 / 100$ \\
\hline \multirow[t]{2}{*}{ Fluoroquinolones } & Ciprofloxacin & 7 & 7 & 8 & 30 & $>50$ & 13 \\
\hline & Levofloxacin & 7 & 7 & 8 & 30 & $>50$ & 13 \\
\hline Rifamycins & Rifampicin & 90 & 70 & 100 & $>200$ & 60 & 80 \\
\hline Chloramphenicol & Chloramphenicol & 10 & 10 & 25 & $>400$ & 15 & 15 \\
\hline Tetracyclines & Tetracycline & 60 & 70 & 180 & 120 & 160 & $>300$ \\
\hline
\end{tabular}

melanin production being correlated to increased resistance to oxidative stress. In contrast to J2315 and BCC1616, strain BCC1617 was not auxotrophic and did not produce a brown pigment, illustrating the known phenotypic variability of these bacteria [21].

\section{B. cenocepacia global gene expression in the presence of antibiotics}

Transcriptomic analysis of strain J2315 was performed on mid-log phase cultures exposed to amikacin, meropenem, trimethoprim-sulfamethoxazole, chlorpromazine and a combination of amikacin and chlorpromazine (Table 2). Expression analysis of the spontaneous mutants was performed with and without each respective antibiotic on which the mutant had been selected; antibiotic exposure was performed at the same antibiotic concentration as used for J2315 and levels above this to induce further responses in the spontaneous mutants (Table 2). Validation of the microarray results was carried out by qPCR analysis of 17 protein coding genes of interest (Additional file 1, Table S1). In all cases the upor downregulation observed by qPCR correlated to the microarray results corroborating previous studies using the $B$. cenocepacia J2315 microarray $[10,11,22]$.

Very few significant alterations in the expression of features on the microarray were observed after exposure of J2315 to amikacin (19 of 8740 probes; Table 2), while exposure to meropenem and trimethoprim-sulfamethoxazole resulted in approximately three times this number of features altering in expression (Table 2). The presence of $0.05 \mathrm{mM}$ chlorpromazine also altered a limited number of features (18/8740), and this doubled with the combination of chlorpromazine and amikacin (Table 2). Overall, a greater number of genes were upregulated than downregulated in each antimicrobial exposure condition (Table 2). The number of differentially expressed genes was significantly higher in all experiments where the antibiotic resistant mutants were compared to J2315 (Table 2). The number of differentially expressed genes was highest in the outbreak isolates BCC1616 and BCC1617, with 255 and 198 differentially expressed genes compared to J2315 (Table 2).

\section{Gene expression in $\mathrm{J} 2315$ and J2315-A in response to amikacin}

The upregulation of tRNAs dominated the transcriptomic response of J2315 to amikacin (15 of the 19 altering genes; Table 2); since this aminoglycoside targets protein synthesis, the alteration of tRNA expression may be correlated to the mode of action of amikacin but, further research will be need to validate this assumption. In terms of protein encoding genes only two were significantly upregulated in the presence of $50 \mu \mathrm{g} / \mathrm{ml}$ amikacin: BCAL1755, a protein with unknown function and the adjacent gene, BCAL1756, a CDS with homology to metal-dependent phosphohydrolases (Table 3). Both were also upregulated in J2315-A (Table 3). The induction of BCAL1756 by the presence of amikacin was 
Table 2 Number of $B$. cenocepacia genes with a $>\mathbf{2}$-fold change in expression

\begin{tabular}{|c|c|c|c|}
\hline \multirow{2}{*}{$\begin{array}{l}\text { B. cenocepacia strain and growth condition } \\
\text { Exposure of J2315 to sub-MIC antimicrobials: }\end{array}$} & \multicolumn{3}{|c|}{$\begin{array}{l}\text { Number of genes significantly altered } \\
\text { in expression ( }>2 \text { fold): }\end{array}$} \\
\hline & Up-regulated & Down-regulated & Total \\
\hline $\mathrm{J} 2315 \mathrm{wt}+50 \mathrm{mg} / \mathrm{L} \mathrm{AMK}$ & 17 & 2 & 19 \\
\hline J2315 wt + 2 mg/L MEM & 53 & 6 & 59 \\
\hline $\mathrm{J} 2315 \mathrm{wt}+10 / 50 \mathrm{mg} / \mathrm{L}$ TMP/SMX & 39 & 17 & 56 \\
\hline $\mathrm{J} 2315 \mathrm{wt}+0.05 \mathrm{mM} \mathrm{CPZ}$ & 13 & 5 & 18 \\
\hline $\mathrm{J} 2315 \mathrm{wt}+0.05 \mathrm{mM} \mathrm{CPZ}+50 \mathrm{mg} / \mathrm{L}$ AMK & 19 & 16 & 35 \\
\hline \multicolumn{4}{|l|}{ J2315 resistant mutants: } \\
\hline J2315-A & 26 & 28 & $54^{\mathrm{a}}$ \\
\hline J2315-A + 50 mg/L AMK & 32 & 50 & $82^{\mathrm{a}}$ \\
\hline $\mathrm{J} 2315-\mathrm{A}+250 \mathrm{mg} / \mathrm{L}$ AMK & 37 & 38 & $75^{\mathrm{a}}$ \\
\hline J2315-M & 39 & 59 & $98^{\mathrm{a}}$ \\
\hline J2315-M + 2 mg/L MEM & 67 & 24 & $83^{\mathrm{a}}$ \\
\hline J2315-M + 8 mg/L MEM & 39 & 74 & $113^{\mathrm{a}}$ \\
\hline J2315-T & 41 & 39 & $80^{\mathrm{a}}$ \\
\hline J2315-T + 10/50 mg/L TMP/SMX & 44 & 38 & $82^{\mathrm{a}}$ \\
\hline J2315-T + 60/300 mg/L TMP/SMX & 52 & 53 & $105^{\mathrm{a}}$ \\
\hline \multicolumn{4}{|l|}{ ST28 outbreak isolates: } \\
\hline BCC1616 & 89 & 166 & 255 \\
\hline BCC1617 & 83 & 115 & 198 \\
\hline
\end{tabular}

${ }^{a}$ The number of genes differentially expressed were significantly different $(p<0.001$; one-way analysis of variance with square root transformation) in the resistant mutants compared to the corresponding condition of J2315 exposed to each respective antibiotic.

confirmed by qPCR (Additional file 1 Table S1). BCAL1756 contains nucleotidyltransferase and phosphotransferase motifs that could possibly confer similar enzyme activities as those present in aminoglycosidemodifying enzymes, and which have been implicated in aminoglycoside resistance [23]. Introduction of the BCAL1755/BCAL1756 region into B. vietnamiensis G4 (see Additional file 1 Table S2 for construct information) which lacks homologous genes in its genome did not result in transformants with an elevated resistance to amikacin. Mobilization of the same construct into $B$. cenocepacia K56-2 (Additional file 1 Table S2), a genetically amenable B. cenocepacia strain that is frequently used as a surrogate model for genetic manipulation due to difficulties associated with J2315 [7], did not increase the amikacin resistance of this strain by insertion of additional copies this locus. The function of these genes was also tested by creating an isogenic knockout mutant in B. cenocepacia strain, K56-2 (Additional file 1 Table S2). In correlation with the gene transfer experiment deletion of genes BCAL1755-6 in mutant K56-2 LL1755-6 did not result in increased susceptibility to aminoglycosides or any other antimicrobial tested (Table 4).

The amikacin-resistant mutant J2315-A demonstrated upregulation of different genes/gene clusters compared to the wild type, regardless of the present or absence of the antibiotic (Table 3). Most conspicuous was the upregulation of a gene cluster on the large chromosome, BCAL3148-3153. One of these genes, BCAL3152 encoded a sigma factor (extracytoplasmatic function subfamily; ECF) and an adjacent anti-sigma factor, BCAL3151. The BCAL3152 sigma factor is highly conserved among Burkholderia species [24]. ECF sigma factors are involved in sensing and regulating the response to changes in the environment, including maintaining cell envelope integrity under stress [25]. The BCAL3148-3153 cluster was not induced in the wild type by sub-inhibitory concentrations of amikacin, but its constitutive upregulation in J2315-A suggested it may play a major role in the general stress response linked to the spontaneous adaptation to an elevated state of antimicrobial resistance.

Another gene cluster found to be constitutively upregulated in J2315-A was a putative acetyltransferase, BCAM 0829a, and a nearby ABC transporter gene, BCAM0831 (Table 3). Limited upregulation of BCAM0829a was observed when J2315 was exposed to amikacin (Table 3) but this was confirmed by qPCR (Additional file 1 Table S1). Acetyltransferases are known mediators of aminoglycoside resistance [23] and $A B C$ transporters often contribute towards multi-drug resistance in E. coli [26], hence, both genes, BCAM0829a and BCAM0831 have plausible roles in functionally mediating resistance to amikacin. However, transfer of the acetyltransferase BCAM0829a into B. vietnamiensis G4 or B. cenocepacia K56-2 failed to alter their 
Table 3 Differentially expressed $B$. cenocepacia genes selected from all conditions tested

\begin{tabular}{|c|c|c|c|c|c|}
\hline \multicolumn{2}{|c|}{$\begin{array}{l}\text { BExperimental condition from which the gene was } \\
\text { selected }\end{array}$} & \multicolumn{4}{|c|}{ Fold change observed under each microarray condition } \\
\hline $\begin{array}{l}\text { Gene } \\
\text { name }\end{array}$ & Annotation & & & & \\
\hline \multicolumn{2}{|c|}{ Exposure to amikacin } & $\begin{array}{c}\mathrm{J} 2315 \mathrm{wt}+ \\
50 \mathrm{mg} / \mathrm{L} \mathrm{AMK}\end{array}$ & J2315-A & $\begin{array}{c}\mathrm{J} 2315-\mathrm{A}+ \\
50 \mathrm{mg} / \mathrm{L} \text { AMK }\end{array}$ & $\begin{array}{c}J 2315-\mathrm{A}+ \\
250 \mathrm{mg} / \mathrm{L} \mathrm{AMK}\end{array}$ \\
\hline BCAL1233 & Putative heat shock Hsp20-related protein & - & 1.95 & 3.47 & 4.92 \\
\hline BCAL1234 & Putative heat shock protein & - & - & 3.00 & 4.43 \\
\hline BCAL1755 & Conserved hypothetical protein & 2.44 & - & 4.74 & 3.47 \\
\hline$\underline{B C A L 1756}$ & Putative metal dependent phosphohydrolase & 1.78 & - & 2.95 & 3.14 \\
\hline BCAL1919 & ClpB heat-shock protein & - & - & - & 3.20 \\
\hline BCAL2442 & Chaperone protein HtpG & - & - & - & 2.39 \\
\hline BCAL3146 & 60 kDa chaperonin 1 & - & - & - & 2.47 \\
\hline BCAL3147 & 10 kDa chaperonin 1 & - & - & - & 2.96 \\
\hline BCAL3148 & $\begin{array}{l}\text { Polyketide cyclase/dehydrase and lipid transport } \\
\text { Family }\end{array}$ & - & 2.14 & 3.27 & 1.95 \\
\hline BCAL3149 & $\begin{array}{l}\text { Outer membrane lipoprotein carrier protein } \\
\text { LolA }\end{array}$ & - & 2.86 & 4.22 & 2.31 \\
\hline BCAL3150 & Putative exported protein & - & 3.15 & 4.34 & - \\
\hline BCAL3151 & putative transmembrane anti-sigma factor & - & 2.76 & 4.43 & 2.31 \\
\hline BCAL3152 & $\begin{array}{l}\text { putative RNA polymerase sigma factor, ECF } \\
\text { subfamily }\end{array}$ & - & 2.94 & 4.77 & 3.40 \\
\hline BCAL3153 & Putative lipoprotein & - & 3.47 & 5.82 & 4.45 \\
\hline BCAL3270 & Putative DnaK chaperone protein & - & - & - & 2.76 \\
\hline BCAM0829a & $\begin{array}{l}\text { RimL, Acetyltransferases, including } \mathrm{N} \text {-acetylases } \\
\text { of ribosomal proteins }\end{array}$ & - & 2.51 & 2.46 & 2.14 \\
\hline BCAM0831 & ABC transporter ATP-binding membrane protein & - & 1.91 & 2.43 & 3.01 \\
\hline BCAS0637 & $60 \mathrm{kDa}$ chaperonin 3 & - & - & - & 6.62 \\
\hline BCAS0638 & 10 kDa chaperonin 3 & - & - & - & 7.88 \\
\hline Exposure to & meropenem & $\begin{array}{c}J 2315 w t+2 \\
\mathrm{mg} / \mathrm{L} \text { MER }\end{array}$ & J2315-M & $\begin{array}{c}J 2315-M+2 \\
\mathrm{mg} / \mathrm{L} \mathrm{MER}\end{array}$ & $\begin{array}{c}\text { J2315-M + } 8 \mathrm{mg} \\
\text { L MER }\end{array}$ \\
\hline BCAL0212 & $\begin{array}{l}\text { Putative phenylacetic acid degra-dation NADH } \\
\text { oxidoreductase PaaE }\end{array}$ & - & - & - & 3.32 \\
\hline BCAL0213 & Phenylacetic acid degradation protein PaaD & - & - & - & 6.61 \\
\hline$\underline{\text { BCAL0214 }}$ & Phenylacetic acid degradation protein PaaC & - & - & - & 3.14 \\
\hline BCAL0215 & Phenylacetic acid degradation protein PaaB & - & 8.01 & 6.48 & 3.81 \\
\hline BCAL0216 & Phenylacetic acid degradation protein PaaA & - & 14.83 & 10.03 & 6.79 \\
\hline BCAL0404 & Phenylacetate-coenzyme A ligase & - & - & - & 2.58 \\
\hline BCAL0405 & Phenylacetic acid degradation protein Paal & - & - & - & 2.75 \\
\hline BCAL0406 & Probable enoyl-CoA hydratase PaaG & - & 6.28 & - & 3.63 \\
\hline BCAL0407 & Beta-ketoadipyl CoA thiolase & - & - & - & 4.48 \\
\hline BCAL0408 & $\begin{array}{l}\text { Putative phenylacetic acid degradation } \\
\text { oxidoreductase paaZ }\end{array}$ & - & 9.93 & 7.93 & 5.75 \\
\hline BCAL0409 & $\begin{array}{l}\text { Putative phenylacetic acid degra-dation enoyl- } \\
\text { CoA hydratase PaaF }\end{array}$ & - & 2.67 & - & - \\
\hline BCAL1804 & Major Facilitator Superfamily protein & - & -3.45 & -2.70 & -1.85 \\
\hline BCAL1805 & Putative sugar kinase & - & -4.76 & -4.35 & -2.22 \\
\hline BCAL1806 & Conserved hypothetical protein & - & -14.29 & -9.90 & -5.26 \\
\hline BCAM1356 & Putative gluconate 2-dehydrogenase subunit 3 & - & -25.64 & -29.50 & -12.85 \\
\hline BCAM1357 & $\begin{array}{l}\text { Gluconate 2-dehydrogenase flavoprotein } \\
\text { subunit }\end{array}$ & - & -7.14 & -7.30 & -5.52 \\
\hline
\end{tabular}


Table 3 Differentially expressed B. cenocepacia genes selected from all conditions tested (Continued)

\begin{tabular}{|c|c|c|c|c|c|}
\hline BCAM1358 & $\begin{array}{l}\text { Gluconate 2-dehydrogenase cytochrome c } \\
\text { subunit }\end{array}$ & - & -24.69 & -25.38 & -9.80 \\
\hline BCAM1710 & Putative enoyl-CoA hydratase/isomerase & - & 3.23 & - & 4.32 \\
\hline BCAM1711 & Phenylacetate-coenzyme A ligase paaK & - & 12.48 & 11.01 & 5.24 \\
\hline BCAM2165 & Putative beta-lactamase, class A & 53.35 & - & 60.30 & 60.62 \\
\hline BCAS0128 & ABC transporter ATP-binding protein & -2.27 & -2.04 & - & -3.70 \\
\hline BCAS0129 & $\begin{array}{l}\text { Putative binding-protein-dependent transport } \\
\text { system component }\end{array}$ & -2.56 & -2.13 & - & -4.98 \\
\hline BCAS0130 & $\begin{array}{l}\text { Putative } A B C \text { transporter substrate-binding } \\
\text { protein }\end{array}$ & -2.94 & - & -2.48 & -6.25 \\
\hline BCAS0156 & Beta-lactamase, class C & 116.10 & - & 133.10 & 61.12 \\
\hline \multicolumn{2}{|c|}{ Exposure to trimethoprim sulfamethoxazole } & $\begin{array}{l}\mathrm{J} 2315 \mathrm{wt}+ \\
10 / 50 \mathrm{mg} / \mathrm{L} \\
\mathrm{TMP} / \mathrm{SMX}\end{array}$ & J2315-T & $\begin{array}{l}\mathrm{J} 2315-\mathrm{T}+10 / \\
50 \mathrm{mg} / \mathrm{L} \\
\mathrm{TMP} / \mathrm{SMX}\end{array}$ & $\begin{array}{l}\mathrm{J} 2315-\mathrm{T}+60 / \\
300 \mathrm{mg} / \mathrm{L} \mathrm{TMP} / \\
\mathrm{SMX}\end{array}$ \\
\hline BCAL0145 & Adenosylhomocysteinase & 1.77 & - & - & 2.26 \\
\hline BCAL0147 & 5,10-methylenetetrahydro-folate reductase & 1.61 & - & - & 2.07 \\
\hline BCAM0186 & Lectin & 2.90 & - & - & - \\
\hline BCAM1869 & Conserved hypothetical protein & - & -3.68 & -4.13 & -2.09 \\
\hline BCAM1870 & $\mathrm{N}$-acylhomoserine lactone synthase Cepl & - & -15.48 & -14.95 & -3.51 \\
\hline BCAM1871 & Conserved hypothetical protein & 2.03 & -14.88 & -12.90 & -3.73 \\
\hline BCAM2549 & $\begin{array}{l}\text { Multidrug efflux system outer membrane } \\
\text { protein }\end{array}$ & - & 138.20 & 111.80 & 35.80 \\
\hline BCAM2550 & Multidrug efflux system transporter protein & - & 108.80 & 103.60 & 30.79 \\
\hline BCAM2551 & Multidrug efflux system transport protein CeoA & - & 296.90 & 341.50 & 55.38 \\
\hline BCAM2552 & Putative hydrolase & - & 187.40 & 167.50 & 45.93 \\
\hline BCAM2554 & LysR family regulatory protein & - & 4.34 & 4.36 & 2.40 \\
\hline BCAS0292 & Conserved hypothetical protein & 3.41 & -6.02 & -4.03 & - \\
\hline BCAS0293 & Nematocidal protein AidA & 8.56 & -6.02 & -5.65 & -2.67 \\
\hline BCAS0409 & $\mathrm{ZmpA}$ & 1.99 & - & - & - \\
\hline \multicolumn{2}{|c|}{ Exposure to chlorpromazine } & $\begin{array}{c}J 2315 \mathrm{wt}+ \\
0.05 \mathrm{mM} \mathrm{CPZ} \\
\end{array}$ & $\begin{array}{c}\mathrm{J} 2315 \mathrm{wt}+0.05 \mathrm{mM} \mathrm{CPZ}+ \\
50 \mathrm{mg} / \mathrm{L} \mathrm{AMK}\end{array}$ & & \\
\hline BCAL1233 & Putative heat shock Hsp20-related protein & - & 2.98 & & \\
\hline BCAL1234 & Putative heat shock protein & - & 2.40 & & \\
\hline BCAL1755 & Conserved hypothetical protein & - & 2.07 & & \\
\hline BCAL1756 & Conserved hypothetical protein & 2.04 & 1.82 & & \\
\hline BCAM0923 & Putative lipoprotein & 11.00 & 11.33 & & \\
\hline BCAM0924 & $\begin{array}{l}\text { Two-component regulatory system, response } \\
\text { regulator protein }\end{array}$ & 4.85 & 4.63 & & \\
\hline BCAM0925 & $\begin{array}{l}\text { Multidrug efflux system outer membrane } \\
\text { protein }\end{array}$ & 12.80 & 16.51 & & \\
\hline BCAM0926 & Multidrug efflux system transporter protein & 17.75 & 27.45 & & \\
\hline BCAM0927 & Multidrug efflux system transport protein & 13.75 & 22.43 & & \\
\hline BCAM2186 & $\begin{array}{l}\text { Putative macrolide-specific efflux system } \\
\text { transport protein }\end{array}$ & 1.96 & 2.04 & & \\
\hline BCAM2187 & Putative ThiJ/Pfpl family protein & 1.60 & 2.02 & & \\
\hline BCAS0167 & Squalene-hopene cyclase & 4.36 & 5.35 & & \\
\hline BCAS0168 & TetR family regulatory protein & 2.33 & 2.81 & & \\
\hline BCAS0638 & $10 \mathrm{kDa}$ chaperonin 3 & & 4.18 & & \\
\hline
\end{tabular}


Table 4 B. cenocepacia K56-6 deletion mutants and their phenotype

\begin{tabular}{|c|c|c|c|c|}
\hline $\begin{array}{l}\text { Mutant } \\
\text { name }\end{array}$ & $\begin{array}{l}\text { Gene(s) } \\
\text { deleted }\end{array}$ & Gene annotation & $\begin{array}{c}\text { Relevant experiment/microarray } \\
\text { observation }\end{array}$ & Phenotype $^{a}$ \\
\hline $\begin{array}{c}\mathrm{K} 56- \\
2 \Delta \mathrm{L} 1755- \\
6\end{array}$ & $\begin{array}{l}\text { BCAL1755 } \\
\text { BCAL1756 }\end{array}$ & $\begin{array}{c}\text { Hypothetical } \\
\text { protein } \\
\text { Phosphohydrolase }\end{array}$ & $\begin{array}{l}\text { Upregulated in the presence of amikacin, in } \\
\qquad J 2315-A \text { and in BCC } 1617\end{array}$ & None observed \\
\hline $\begin{array}{c}\mathrm{K} 56- \\
2 \Delta \mathrm{M} 0831 \\
\end{array}$ & BCAM0831 & $A B C$ transporter & Upregulated in the presence of amikacin & None observed \\
\hline $\begin{array}{c}\mathrm{K} 56- \\
2 \Delta \mathrm{SO}^{-} \mathrm{293-} \\
2\end{array}$ & $\begin{array}{l}\text { BCAS0292 } \\
\text { BCAS0293 }\end{array}$ & $\begin{array}{l}\text { Hypothetical } \\
\text { protein } \\
\text { Nematocidal } \\
\text { protein AidA }\end{array}$ & Upregulated in the presence of TMP/SMX & None observed \\
\hline $\begin{array}{c}\mathrm{K} 56- \\
2 \Delta \mathrm{M} 0924\end{array}$ & BCAM0924 & $\begin{array}{l}\text { Response regulator } \\
\text { protein }\end{array}$ & $\begin{array}{l}\text { Upregulated in the presence of } \\
\text { chlorpromazine }\end{array}$ & None observed \\
\hline $\begin{array}{l}\mathrm{K} 56- \\
2 \Delta \mathrm{M} 0925- \\
7\end{array}$ & $\begin{array}{l}\text { BCAM0925 } \\
\text { BCAM0296 } \\
\text { BCAM0297 }\end{array}$ & $\begin{array}{l}\text { Multidrug efflux } \\
\text { system OMP } \\
\text { Multidrug efflux } \\
\text { system protein } \\
\text { Multidrug efflux } \\
\text { system protein }\end{array}$ & $\begin{array}{l}\text { Upregulated in the presence of } \\
\text { chlorpromazine }\end{array}$ & $\begin{array}{l}\text { Increased susceptibility for chlorhexidine (14 } \mu \mathrm{g} / \mathrm{ml} \text {, wt } \\
\qquad 22 \mu \mathrm{g} / \mathrm{ml}) \\
\text { Increased susceptibility for azithromycin }(100 \mu \mathrm{g} / \mathrm{ml} \text {, wt } \\
150 \mu \mathrm{g} / \mathrm{ml}) \\
\text { Decreased growth rate in the presence of } 1.0 \mathrm{mM} \\
\text { chlorpromazine }(\mu=0.49 \text {, wt } \mu=0.55)\end{array}$ \\
\hline $\begin{array}{c}\mathrm{K} 56- \\
2 \Delta \mathrm{M} 2186- \\
8\end{array}$ & $\begin{array}{l}\text { BCAM2186 } \\
\text { BCAM2187 } \\
\text { BCAM2188 }\end{array}$ & $\begin{array}{l}\text { Efflux system } \\
\text { transport protein } \\
\text { ABC-type efflux } \\
\text { carrier protein } \\
\text { Outer membrane } \\
\text { efflux protein } \\
\end{array}$ & $\begin{array}{l}\text { Upregulated in the presence of } \\
\text { chlorpromazine }\end{array}$ & None observed \\
\hline $\begin{array}{c}\mathrm{K} 56- \\
2 \Delta \mathrm{S} 0167\end{array}$ & BCAS0167 & $\begin{array}{l}\text { Squalene-hopene } \\
\text { cyclase }\end{array}$ & $\begin{array}{l}\text { Upregulated in the presence of } \\
\text { chlorpromazine }\end{array}$ & $\begin{array}{l}\text { Increased susceptibility for chlorhexidine }(13 \mu \mathrm{g} / \mathrm{ml} \text {, wt } \\
\qquad 22 \mu \mathrm{g} / \mathrm{ml}) \\
\begin{array}{l}\text { Decreased growth rate in the presence of } 1.0 \mathrm{mM} \\
\text { chlorpromazine }(\mu=0.62 \text {, wt } \mu=0.80)\end{array}\end{array}$ \\
\hline $\begin{array}{c}\mathrm{K} 56^{-} \\
2 \triangle \mathrm{S} 0081\end{array}$ & BCAS0081 & $A B C$ transporter & $\begin{array}{l}\text { Upregulated in outbreak strains BCC1616 } \\
\text { and BCC1617 }\end{array}$ & $\begin{array}{l}\text { Increased susceptibility for chlorhexidine }(14 \mu \mathrm{g} / \mathrm{ml} \text {, wt } \\
22 \mu \mathrm{g} / \mathrm{ml}) \\
\text { Increased susceptibility for tetracycline }(100 \mu \mathrm{g} / \mathrm{ml} \text {, wt } \\
150 \mu \mathrm{g} / \mathrm{ml})\end{array}$ \\
\hline
\end{tabular}

${ }^{a}$ The following antibiotics and antimicrobials were tested on all mutants, except K56-2 $\Delta$ S0167: amikacin, tobramycin, meropenem, ceftazidime, trimethoprim, azithromycin, erythromycin, levofloxacin, tetracycline, chloramphenicol, chlorhexidine

susceptibility to amikacin, gentamicin and tobramycin (with or without chloropromazine), and deletion of the associated $\mathrm{ABC}$ transporter gene BCAM0831 in mutant $\mathrm{K} 56-2 \Delta \mathrm{M}$ 0831 also did not reveal an antimicrobial phenotype (Table 4).

\section{Gene expression in J2315 and J2315-M in response to meropenem}

The global gene expression response of B. cenocepacia to meropenem was characterised by upregulation of predictable factors such as beta-lactamases and of novel enzymes like those linked to the phenylacetic acid (PA) degradation pathway (Table 3). BCAS0156, a class C beta-lactamase encoded on the small chromosome was the most upregulated gene seen when the wild type was exposed to meropenem; a class A beta-lactamase, BCAM2165, encoded on the medium chromosome was also highly expressed (Table 3). Interestingly, neither beta-lactamase was significantly altered in expression in the meropenem resistant mutant in the absence of the antibiotic (Table 3), indicating that these enzymes were not primarily involved in the elevated resistance phenotype of J2315-M (Table 1).
Located 135 bp upsteam of the class A beta-lactamase BCAM2165 was a LysR family regulator BCAM2166, with $90 \%$ homology to and in a location corresponding to that of penR previously described in "P. cepacia" [27] (now known to be a $B$. multivorans strain). This region is conserved in all completed Burkholderia genomes and Trépanier et al. [27] showed that penR controlled the transcription of the class A beta-lactamase penA with a putative binding site mapped to a region $130 \mathrm{bp}$ upstream of the beta-lactamase, directly adjacent to the regulator sequence. A motif search revealed the same binding site in J2315, upstream of both BCAM2165 and BCAS0156, suggesting that they may be co-regulated and possibly under the control of the BCAM2166 regulator.

Although both beta-lactamases were upregulated in the presence of meropenem, it was not known which, if any, is active against the antibiotic. Carbapenem hydrolyzing class A beta-lactamases have been reported for Klebsiella pneumoniae [28]. A class A penB beta-lactamase has been characterised in B. cenocepacia [29] that is active against penicillin and cephalosporins, but has only a marginal ability to degrade meropenem and imipenem. 
A plasmid-encoded class $C$ beta-lactamase with weak imipenemase activity has also been reported [30]. To clarify the involvement of BCAM2165 in meropenem inactivation by B. cenocepacia, clavulanic acid was tested as a class A-specific beta-lactamase-inhibitor, but it failed to reduce the MIC for meropenem even at concentrations as high as $64 \mathrm{mg} / \mathrm{L}$ (data not shown). The role of the class C beta-lactamase, BCAS0156 was tested by complementation into B. vietnamiensis $\mathrm{G} 4$ which lacks this gene (see Additional file 1 Table S2 for construct). The resulting transformant showed an increase in MIC for cefotaxime (from 8 to $35 \mathrm{mg} / \mathrm{L}$ ), ceftazidime (from 7 to $50 \mathrm{mg} / \mathrm{L}$ ), imipenem (from 8 to $40 \mathrm{mg} / \mathrm{L}$ ) and piperacillin (from 4 to $15 \mathrm{mg} / \mathrm{L}$ ), but the MIC for meropenem $(0.35 \mathrm{mg} / \mathrm{L})$ and aztreonam $(6 \mathrm{mg} / \mathrm{L})$ remained unchanged from that of wild type B. vietnamiensis G4. When the same construct was mobilized into B. cenocepacia $\mathrm{K} 56-2$, the MIC for cefotaxime (300 to $400 \mathrm{mg} / \mathrm{L}$ ) and ceftzidime ( 40 to $45 \mathrm{mg} / \mathrm{L}$ ) increased, but the remaining antibiotic MICs were unaltered. Addition of chlorpromazine to the complemented strains did not alter their antibiotic susceptibility further. A functional role for BCAS0156 in mediating high level beta-lactam resistance was therefore supported, but interestingly not for meropenem as a specific substrate for this class $\mathrm{C}$ beta-lactamase.

Three gene clusters annotated as phenylacetic acid degradation enzymes [31,32] were upregulated in mutant J2315-M regardless of the presence or absence of the meropenem (Table 3). In B. cenocepacia, these genes are organised as follows: two gene clusters on the large chromosome (BCAL0212-0216, BCAL0404-0409) and one gene cluster on the medium chromosome (BCAM1710-1712). All three clusters appeared largely co-regulated from the microarray data and a MEME search revealed a common regulatory motif [33] for all three locations, upstream of BCAL0216, BCAL0408 and BCAM1712 respectively. A MAST analysis revealed the same regulatory motif to be present upstream of the PA degradation genes in all genome sequenced Burkholderia species. Upregulation of BCAL0216, BCAL0408, and BCAL1711/12 was confirmed by qPCR (Additional file 1 Table S1).

Two sets of genes involved in glucose transport and metabolism via the pentose phosphate pathway were substantially down regulated in the resistant mutant J2315M: BCAL1804-1806 and BCAM1356-1358 (Table 3). Growth curve analysis showed that J2315-M grew at less than half the growth rate on glucose than J2315. The PA catabolic enzymes have been shown to be under glucose catabolite repression in B. cenocepacia [33]. Our data therefore suggested that for J2315-M to achieve the upregulation of PA genes and increase its meropenem resistance, it had to down regulate the glucose transport and metabolism genes to lower the intracellular glucose concentration. The resulting slower growth rate of J2315-M in presence of glucose may also be an advantageous phenotype for surviving antimicrobial exposure, analogous to the alterations seen in small colony variants [34].

To elucidate if the PA catabolic enzymes aid resistance to antibiotics, MIC values in the presence and absence of glucose $(20 \mathrm{mM})$ in LB medium were determined. The presence of glucose resulted in reductions of $\geq 2$-fold in J2315's MIC for meropenem (50 to $15 \mathrm{mg} / \mathrm{L}$ ), ceftazidime (275 to $160 \mathrm{mg} / \mathrm{L})$, chloramphenicol (16 to $8 \mathrm{mg} / \mathrm{L}$ ) and tetracycline (50 to $10 \mathrm{mg} / \mathrm{L}$ ); no change was observed for amikacin, tobramycin, erythromycin, levofloxacin and trimethoprim-sulfamethoxazole. A panel of 17 closely related B. cenocepacia were also tested and 7 out of 17 also demonstrated a reduction in meropenem MIC in the presence of $20 \mathrm{mM}$ glucose (data not shown). Analysis of PA gene expression directly correlated to these phenotypic observations, being considerably reduced in J2315 (48-fold by qPCR for BCAL0216) in the presence of glucose. Expression of this gene was unaltered by addition of glucose for B. cenocepacia K56-2, which did not demonstrate the same MIC reduction for meropenem.

The strain to strain variability of this putative catabolite repression response suggest that the regulation of central metabolism in B. cenocepacia is highly complex; given the number of paralogous metabolic pathways present in Burkholderia genomes [35] such plasticity is not surprising. qPCR showed that the expression of the beta-lactamases (BCAM2165 and BCAS0156) was not affected by the presence of glucose in $\mathrm{J} 2315$ indicating that these degradative antibiotic resistance enzymes were not catabolite repressed. The role of the PA degradation enzymes in Burkholderia is not yet fully understood, but recently it was shown that PA pathway is necessary for full pathogenicity during Caenorhabditis elegans infection [36]. The linkage of PA degradation to the phenomenon of spontaneous antibiotic resistance in $B$. cenocepacia adds further complexity to the central role aromatic metabolism plays in the biology of these microorganisms.

\section{Gene expression in J2315 wt and J2315-T in response to trimethoprim-sulfamethoxazole}

The gene encoding a homologue of AidA (BCAS0293), a quorum sensing regulated gene required for full virulence of B. cenocepacia H111 during C. elegans infection [37] was the most upregulated gene when wild type J2315 was exposed to sub-inhibitory levels of TMP-SMX (Table 3). Other quorum sensing regulated genes such as the zinc metalloprotease [38], ZmpA (BCAS0409), and the lectin encoding BCAM0186 [11] were also upregulated. Few other significant alterations were made by J2315 in response of sub-lethal amounts of TMP-SMX (Table 3). Deletion of BCAS0293 together with the adjacent 
BCAS0292 in mutant K56-2 $\Delta$ S0293-2 did not alter its susceptibility to trimethoprim, sulfamethoxazole, or any other antimicrobials (Table 4).

The TMP-SMX resistant mutant J2315-T also altered the expression of a limited number of genes, however, the most conspicuous change it made was a strong and constitutive upregulation of an efflux pump of the RND family, BCAM2549-2552 (Table 3). This is the J2315 homologue of the ceo multidrug efflux pump operon described by Nair et al. [39] consisting of the three parts of the efflux pump (BCAM2549-2551) and a hydrolase/ lipase (BCAM2552). The MIC data for J2315-T showed increased resistance to trimethoprim, fluorquinolones, chloramphenicol and tetracyclines (Table 1; all are known substrates for this pump), a phenotype consistent with the substrate spectrum of the ceo efflux pump described by Nair et al. [39] and thus corroborating the microarray expression data. Upstream and divergently transcribed from the ceo efflux pump is a LysR family regulatory protein, BCAM2554, that is a homologue of the ceoR transcriptional activator [39]. This regulator was constitutively upregulated in mutant J2315-T (Table 3). Nair et al. [39] had also shown that the pump was upregulated in the presence of salicylate. In contrast to their findings made on B. cenocepacia strain PC121 [39], where salicylate and chloramphenicol were found to induce expression of the ceo efflux pump, we found that both the efflux pump and ceoR in B. cenocepacia J2315 and K56-2 were not inducible by salicylate (as tested by qPCR, data not shown) or sub-inhibitory levels of TMPSMX (Table 3).

\section{Gene expression in J2315 wt in response to chlorpromazine}

Exposure of B. cenocepacia to this potentiator of aminoglycoside activity resulted in significant upregulation of two efflux gene clusters, BCAM0923-0927 and to a lesser extent, BCAM2186-2188 (Table 3). No specific link to amikacin-related gene expression, the antibiotic most potentiated by chlorpromazine, was observed (Table 3). The BCAM2186-2188 pump had homology to a macrolide-specific ABC-type efflux pump system in E. coli [26]. Transfer of the efflux pump genes to B. vietnamiensis G4 or B. cenocepacia K56-2 (Additional file 1 Table S2) did not alter the antimicrobial susceptibility of these strains (either with or without the addition of chlorpromazine). Likewise creation of a $B$. cenocepacia deletion mutant K56-2 $\Delta \mathrm{M} 2186-8$ did not produce an observable phenotype in relation to the antibiotics (with or without chlorpromazine) examined in this study (Table 4).

In relation to the other chlorpromazine activated efflux system, BCAM0926 and BCAM0927, were closely related to MexD and MexC, respectively, components of the
MexCD-OprJ efflux pump in $P$. aeruginosa [40]. BCAM0925, an outer membrane protein, is most similar to OprM, which is part of the MexAB-OprM efflux pump in $P$. aeruginosa [40]. BCAM0924 is the response regulator part of a two component regulatory system that may control expression of the efflux pump; its role was investigated by the construction of a deletion mutant K56-2 $\Delta$ M0924 (Table 4). The mutation did not alter its chlorpromazine or antibiotic MIC (Table 4). The expression of the structural pump genes, BCAM0926-0927, was also still induced by chlorpromazine in the deletion mutant suggesting that BCAM0924 was not critical for regulation of the adjacent efflux pump (data not shown).

To further investigate the role of the efflux pump structural genes BCAM0925-0927, a K56-2 deletion mutant spanning all 3 genes was constructed (Table 4). The K56-2 $\Delta$ M0925-7 mutant demonstrated increased susceptibility to the disinfectant chlorhexidine and the antibiotic azithromycin, but no alteration in susceptibility to other antibiotics. Growth curve analysis of the K56-2 $\Delta$ M0925-7 mutant revealed a 10\% slower growth rate in the presence of chlorpromazine compared to the parent strain. qPCR analysis of the K56-2 parent strain showed that chlorhexidine, as well as chlorpromazine induced the efflux pump gene BCAM0927, 345-fold in the presence of $5 \mu \mathrm{g} / \mathrm{ml}$ chlorhexidine and 125-fold in the presence of $0.05 \mathrm{mM}$ chlorpromazine. Chlorhexidine, like chlorpromazine is a cationic compound known to interact with and damage cellular membranes [41], hence it is logical that both compounds induce the efflux pump and that the efflux mutant demonstrated sensitivity to this disinfectant. Chlorhexidine is also known to induce the Pseudomonas aeruginosa MexCDOprJ efflux pump [41]. Since the BCAM0925-0927 efflux operon shares considerable homology with latter $P$. aeruginosa system, the mutant phenotype also suggests that the pump may play a role in chlorhexidine efflux in B. cenocepacia. Why deletion of the pump led to an alteration in susceptibility to azithromycin is not known.

Another gene cluster upregulated in the presence of chlorpromazine was a squalene-hopene cyclase, BCAS0167, and an adjacent, divergently transcribed response regulator, BCAS0168 (Table 3). Squalene-hopene cyclase is involved in the synthesis of hopanoids, the prokaryotic equivalent of steroids [42] which may function to counter the effect of membrane disrupting agents on bacterial cells. A deletion mutant of BCAS0167, K56-2 $\Delta$ S0167, demonstrated reduced growth rate in the presence of chlorpromazine and chlorhexidine, as well as an increased susceptibility to chlorhexidine (Table 4). Since the squalene-hopene cyclase gene and surrounding region is highly conserved in several Bcc genomes (B. cenocepacia, B. multivorans, B. lata and B. 
ambifaria) these data suggest it plays an integral role in the intrinsic resistance of Burkholderia to membrane disrupting antimicrobial agents.

\section{Gene expression in the pan-resistant CF outbreak isolates BCC1616 and BCC1617}

The most pronounced change in expression profiles of both ET12 outbreak isolates was the downregulation of genes involved in flagella production and in chemotaxis (Table 5) compared to J2315. BCC1616 and BCC1617 also downregulated expression of their cable pilus genes (Table 5). The lack of flagella and chemotaxis gene expression correlated directly to the non-motile phenotype of the outbreak isolates, in contrast to J2315 which was motile (Additional file 1, Figure S1). During rapid growth in a sputum-based medium J2315 upregulates genes involved in production of the flagellum [10]. This may reflect a short term response of $B$. cenocepacia to early growth during infection, where flagella and motility serve as important virulence factors [43]. Lack of motility has been observed in P. aeruginosa CF isolates from chronic infection [18] and as a global gene expression adaptation to growth in sputum [44]. The stable non-motile phenotype and genotype of the recent ET12 clinical strains suggest that B. cenocepacia may in time also adapt to the same phenotype associated with $P$. aeruginosa from chronic CF infection.

Both the outbreak isolates had upregulated genes involved in transport and efflux, restriction modification, and transposition as follows (Table 5). An ABC membrane transport protein (BCAS0081; 41-fold) and adjacent hypothetical protein with possible hydrolytic activity (BCAS0082; 35-fold) were highly expressed. The transport protein BCAS0081 contains both an ATP binding cassette and transmembrane components, and has homology to the $m d l B$ gene of $E$. coli which is implicated in multidrug resistance [45]. Deletion of BCAS0081 in mutant K56-2 $\triangle$ S0081 resulted in increased susceptibility to tetracycline and chlorhexidine, but did not alter the MIC for the other antimicrobial agents tested (Table 4). These data validate the microarray observed upregulation of BCAS0081 and demonstrate it does play a role in the antimicrobial resistance of $B$. cenocepacia.

Also highly upregulated in both strains were genes of a type I restriction modification system (BCAL0414-0420; Table 4). In J2315, the first gene in this operon is a pseudogene mutated with an insertion sequence (IS) that may prevent expression of the entire downstream gene cluster. PCR amplification and sequence analysis of this region revealed that $\mathrm{BCC} 1616$ and $\mathrm{BCC} 1617$ do not possess the same IS mutation, hence allowing overexpression of the genes as detected by the microarray analysis. Mutation of the putative DNA methylase, BCAL0417, in this cluster results in the attenuation of $B$. cenocepacia virulence in a rat lung model of chronic lung infection (mutant 16_E1 [46]). The DNA modification conferred by the gene cluster may also play a role in surviving the damage caused by hydroxyl radicals which are released when bacteria are exposed to bactericidal antibiotics [47]. Since the type I restriction modification cluster is clearly transcriptionally activated in the outbreak strains, it will be interesting to follow up if their expression has provided them with a resistance and virulence advantage compared to J2315 as an ancestral ET12 isolate.

Another response conserved between the two outbreak isolates was the upregulation of transposase encoding genes within ISBcen9 (multiple probes were on the microarray; see BCAL0044 and BCAM2637, Table 5). The IS profiles of $B$. cenocepacia isolates of the same MLST strain type have been recently shown to vary markedly and oxidative stress was linked to this IS movement [48]. The upregulation of the ISBcen9 transposase in these recent outbreak isolates may indicate that these strains are hypermutable with regard to this IS. This may allow very rapid phenotypic switches to occur within individual bacteria in the infecting population and alter their pathogenicity.

When examined individually, the two outbreak isolates demonstrated several global gene expression characteristics that had been observed in the antibiotic resistant B. cenocepacia J2315 derivatives. BCC1616 upregulated the PA degradation enzyme genes (Table 5), that were also constitutively upregulated in J2315-M (Table 2). These data re-enforce the hypothesis that the ability of B. cenocepacia to switch metabolism to alternative pathways in terms of aromatic hydrocarbon degradation plays a critical role in its spontaneous antibiotic resistance. It had also upregulated the class A beta-lactamase (BCAM2165) that was induced in J2315 and J2315-M upon meropenem exposure (Table 3 ). Phenotypically, BCC1616 possessed the same elevated resistance to betalactam antibiotics that J2315-M had developed after meropenem selection (Table 1), and its meropenem MIC could be reduced by growth in the presence glucose (data not shown). Genes found upregulated in the amikacinresistant J2315-A derivative (BCAL3148-3152; Table 5) were also constitutively over-expressed in BCC1616, again correlated to high aminoglycoside resistance of this isolate (Table 1).

Several differentially expressed genes were specific to isolate BCC1617. Genes involved in the p-hydroxybenzoate degradation pathway were highly upregulated (BCAL0057-0063, BCAM2568, and the IclR family positive regulator protein BCAM2569; Table 5). Since the PA pathway genes were not significantly altered in BCC1617, it would be interesting to follow up if the p-hydroxybenzoate degradation pathway may provide an alternative metabolic shift for $B$. cenocepacia to evolve 
Table 5 Selected genes differentially expressed in the recent B. cenocepacia outbreak strains BCC1616 and BCC1617 compared to B. cenocepacia J2315

\begin{tabular}{|c|c|c|c|}
\hline \multirow[t]{2}{*}{ Functional class and gene name } & \multirow[t]{2}{*}{ Annotation } & \multicolumn{2}{|c|}{ Fold change in expression ${ }^{11}$} \\
\hline & & BCC1616 & BCC1617 \\
\hline \multicolumn{4}{|l|}{ Motility and chemotaxis } \\
\hline BCAL0113 & B-type flagellar hook-associated protein 2 & -18.80 & -11.33 \\
\hline BCAL0114 & flagellin (type II) & -38.91 & -24.51 \\
\hline BCAL0126 & chemotaxis protein MotA & -3.22 & -2.41 \\
\hline BCAL0127 & chemotaxis protein MotB & -5.68 & - \\
\hline BCAL0128 & chemotaxis two-component response regulator $\mathrm{CheY}$ & -6.76 & -2.95 \\
\hline BCAL0129 & chemotaxis two-component sensor kinase CheA & -6.80 & -3.26 \\
\hline BCAL0130 & chemotaxis protein CheW & -3.11 & -2.82 \\
\hline BCAL0521 & flagellar FliJ protein & -4.31 & -3.28 \\
\hline BCAL0576 & flagellar hook-associated protein 1 (HAP1) & -11.57 & -5.38 \\
\hline BCAL0577 & flagellar hook-associated protein 3 (HAP3) & -14.33 & -6.21 \\
\hline BCAL0762 & putative methyl-accepting chemotaxis protein & -3.32 & -2.99 \\
\hline BCAM1503 & putative methyl-accepting chemotaxis protein & -16.92 & -9.90 \\
\hline BCAL1662 & putative methyl-accepting chemotaxis protein & -4.98 & -2.57 \\
\hline BCAM1804 & methyl-accepting chemotaxis protein & -12.56 & -6.71 \\
\hline BCAM2564 & putative aerotaxis receptor & -6.45 & -3.52 \\
\hline \multicolumn{4}{|l|}{ Cable pilus biosynthesis } \\
\hline BCAM2758 & two-component regulatory system, sensor kinase protein & -2.19 & -2.63 \\
\hline BCAM2759 & putative minor pilin and initiator & - & -3.69 \\
\hline BCAM2760 & putative outer membrane usher & -2.15 & -2.96 \\
\hline BCAM2761 & giant cable pilus & -2.97 & -6.90 \\
\hline BCAM2762 & giant cable pilus chaperone protein & -4.44 & -10.00 \\
\hline \multicolumn{4}{|c|}{ Transport, efflux and antimicrobial resistance } \\
\hline BCAL1674 & multidrug efflux system AmrA protein & - & 2.49 \\
\hline BCAL1756 & Putative metal dependent phosphohydrolase & - & 1.97 \\
\hline BCAM2165 & putative beta-lactamase, class $\mathrm{A}$ & 2.45 & - \\
\hline BCAS0081 & ABC transporter ATP-binding membrane protein & 35.39 & 33.37 \\
\hline BCAS0082 & Hydrolase of the alpha/beta superfamily & 41.13 & 30.37 \\
\hline \multicolumn{4}{|l|}{ Restriction modification } \\
\hline BCAL0414_J_1 & type I modification component of restriction-modification system (pseudogene) & 23.04 & 24.84 \\
\hline BCAL0418 & type I restriction enzyme specificity protein & 12.59 & 10.77 \\
\hline BCAL0420 & type I restriction component of type I restriction-modification system & 3.79 & 3.04 \\
\hline \multicolumn{4}{|l|}{ Transposition } \\
\hline BCAL0044 & putative transposase & 3.75 & 2.91 \\
\hline BCAM2637 & putative transposase & 7.42 & 3.04 \\
\hline \multicolumn{4}{|l|}{ Aromatic hydrocarbon catabolism } \\
\hline BCAL0212 & putative phenylacetic acid degradation NADH oxidoreductase PaaE & 2.29 & - \\
\hline BCAL0213 & phenylacetic acid degradation protein PaaD & 5.19 & - \\
\hline BCAL0215 & phenylacetic acid degradation protein $\mathrm{PaaB}$ & 3.31 & - \\
\hline BCAL0216 & phenylacetic acid degradation protein PaaA & 3.06 & - \\
\hline BCAL0405 & phenylacetic acid degradation protein Paal & 2.49 & - \\
\hline BCAL0406 & probable enoyl-CoA hydratase PaaG & 2.54 & - \\
\hline BCAL0407 & beta-ketoadipyl CoA thiolase & 4.38 & - \\
\hline BCAM1711 & phenylacetate-coenzyme A ligase paaK & 3.44 & - \\
\hline BCAM0058 & 3-oxoadipate CoA-transferase subunit A & - & 61.45 \\
\hline
\end{tabular}


Table 5 Selected genes differentially expressed in the recent B. cenocepacia outbreak strains BCC1616 and BCC1617 compared to B. cenocepacia J2315 (Continued)

\begin{tabular}{|c|c|c|c|}
\hline BCAM0059 & 3-oxoadipate CoA-transferase subunit B & - & 70.43 \\
\hline BCAM0060 & 3-carboxy-cis, cis-muconate cycloisomerase & - & 30.44 \\
\hline BCAM0061 & putative 3-oxoadipate enol-lactonase I & - & 37.36 \\
\hline BCAM0062 & 4-carboxymuconolactone decarboxylase & - & 48.08 \\
\hline BCAM0063 & putative 4-hydroxybenzoate transporter & - & 5.79 \\
\hline BCAM2568 & putative beta-ketoadipyl CoA thiolase & - & 35.88 \\
\hline BCAM2569 & ICIR family regulatory protein & - & 13.08 \\
\hline \multicolumn{4}{|c|}{ Miscellaneous genes } \\
\hline BCAL0297 & putative thiamine biosynthesis oxidoreductase & 5.69 & 2.50 \\
\hline BCAL1104 & thiamine biosynthesis protein & 4.24 & 3.01 \\
\hline BCAL1756 & Putative metal dependent phosphohydrolase & - & 1.97 \\
\hline BCAL3152 & putative RNA polymerase sigma factor, ECF subfamily & 5.26 & -8.93 \\
\hline BCAL3153 & putative lipoprotein & 6.89 & -13.04 \\
\hline BCAM0186 & lectin & 7.89 & - \\
\hline BCAS0125 & conserved hypothetical protein & 31.75 & - \\
\hline BCAS0126 & MarR family regulatory protein/acetyltransferase & 9.18 & - \\
\hline BCAS0292 & conserved hypothetical protein & 3.98 & - \\
\hline
\end{tabular}

its antibiotic resistance. A specific resistance determinant upregulated in BCC1617 was an efflux pump (BCAL1674; Table 5) that is a homologue of the AmrAB [49] and of BpeAB [50] systems encoded by $B$. pseudomallei. Both the latter systems mediate resistance to aminoglycosides and macrolides in B. pseudomallei and it was notable that BCC1617 possessed very high levels of resistance to tobramycin, azithromycin and erythromycin (Table 1). An adjacent gene BCAL1672, encoding a transcriptional regulator and inactive in J2315 due to a frameshift mutation, does not have the frameshift in BCC1617 as revealed by sequence analysis. Hence, this could in turn allow the upregulation of the efflux pump in the outbreak strain compared to J2315.

BCC1617 also over expressed the phosphohydrolase BCAL1756 which was stably upregulated in the J2315-A amikacin exposed mutant. Other factors possibly contributing to the overall antibiotic resistance in BCC1617 compared to J2315 is the absence of a frameshift mutation in gene BCAL3259, a transport protein annotated as tetracycline resistance protein, and absence of an insertion sequence in BCAM1251, annotated as multidrug resistance transporter. Both latter genes are pseudogenes in J2315 [6] and also in BCC1616 (data not shown). Although their expression did not change in BCC1617, by just being functionally expressed they may mediate increased resistance to antibiotics.

\section{Conclusions}

Our novel transcriptomic analysis of the response of $B$. cenocepacia to antibiotic exposure has demonstrated that it expresses a multitude of genes and different pathways to achieve high levels of resistance. B. cenocepacia J2315 and the clonally related strains we studied are phenotypically and transcriptomically very versatile and can adapt quickly to environmental conditions. A key finding was that once certain antibiotic resistance phenotypes in B. cenocepacia had been selected by a single antibiotic, the changes in the transcriptome were not transient, and were stably maintained in the spontaneous antibiotic resistant mutants. This finding suggests that mutations selected in the spontaneously resistant B. cenocepacia J2315 mutants are stably inherited and do not revert at a high frequency. A change in antibiotic therapy may therefore not reverse a previously acquired $B$. cenocepacia spontaneous antibiotic resistance trait. Our molecular analysis corroborates the results of antibiotic susceptibility testing that demonstrate focussing on a single antibiotic or antibiotic class for therapy has limited efficacy and that multiple antibiotic combinations [14] offer the best means to combat the spontaneous resistance of this pathogen. We have identified multiple novel molecular pathways $B$. cenocepacia utilises to resist sub-MIC levels of antibiotic. However, for many of the genes altering expression in relation to antibiotic exposure we could not prove a direct involvement resistance, with only 3 of the $8 \mathrm{~B}$. cenocepacia antibiotic resistance gene deletion mutants demonstrating increased antimicrobial susceptibility. For spontaneous resistance to single antibiotics, $B$. cenocepacia expresses set of genes which are distinct from those altered by transient subMIC exposure, and which are stably altered in expression irrespective of the presence of the priming antibiotic. 
These findings suggest that spontaneous antibiotic resistance in B. cenocepacia selects multiple individual as well as pleiotropic mutations, stably altering the expression of many genetic pathways; uncovering the location of these mutations by genome re-sequencing and polymorphism analysis in future studies would shed light on why these changes are stably inherited traits in B. cenocepacia. Of the $B$. cenocepacia resistance mechanisms identified, those such as the beta-lactamases, phosphohydrolases, novel efflux pumps and phenylacetic acid pathways genes may be targeted to improve the efficacy of current antibiotics. We may also be able to harness the phenomenon of bacterial catabolite repression by glucose as a novel means to improve the efficacy of aerosolised antibiotics against certain B. cenocepacia during CF infection.

\section{Methods}

\section{Bacterial strains and growth}

B. cenocepacia strains J2315, K56-2, BCC1616 and BCC1617, B. vietnamiensis G4, Escherichia coli strains and plasmids used in this study are shown in Additional file 1, Table S2. Bacteria were grown on Iso-sensitest agar/broth (Oxoid, Basingstoke, UK), Tryptic Soya agar/ broth (TSA/TSB; Oxoid, Basingstoke, UK) Luria Bertani agar/broth (LBA/LB; Sigma-Aldrich, St. Louis, MO, USA) or minimal medium (BSM [51]) as required. Strains BCC1616 and BCC1617 were from an outbreak of $B$. cenocepacia ET12 infection among CF patients that occurred in 2008 [15] and were confirmed to be the same sequence type as 22315 (ST-28 [6]) by sequence analysis of the phaC, gyrB and $\operatorname{trp} B$ genes [52]. The presence or absence of pseudogenes in BCC1616/1617 in comparison to strain J2315 was also determined using PCR (primer sequences are shown in Additional file 1, Table S3) and sequencing. P. aeruginosa ATCC 27853 was used as an antibiotic susceptible reference strain for antimicrobial analysis. LB was supplemented with $20 \mathrm{mM}$ glucose for testing of catabolite repression and antibiotic susceptibility as described below. Bacterial stocks were maintained at $-80^{\circ} \mathrm{C}$ as suspensions of fresh plate growth in TSB containing $8 \%$ dimethyl sulphoxide.

Microbial growth characteristics were determined using a Bioscreen Automated Microbial Growth Analyzer (Bioscreen C, Oy Growth Curves AB, Finland). Cells were grown in honeycomb microtiter plates at $37^{\circ} \mathrm{C}$ with $200 \mu \mathrm{l}$ medium per well and an inoculum of $5 \times 10^{5}$ colony forming units (CFU) per ml. Optical density was measured every $5 \mathrm{~min}$ at 420-580 $\mathrm{nm}$ wideband after shaking for 5 seconds. Swimming motility [18] was determined in Isosensitest medium with $0.3 \%$ agar. Triplicate cultures were grown in each experiment and data from two biological replicates analyzed.

Spontaneous mutants with elevated antibiotic resistance were selected by plating strain J2315 onto Iso-sensitest agar containing antibiotic concentrations that were approximately double the MIC as follows: Amikacin (AMK) $300 \mathrm{mg} / \mathrm{L}$; meropenem (MEM) $15 \mathrm{mg} / \mathrm{L}$; and trimethoprim (TMP) in combination with sulfamethoxazole (SMX), 100 and $500 \mathrm{mg} / \mathrm{L}$, respectively. The mutation frequency was calculated by dividing the total number spontaneous mutants by the total number of viable cells plated onto each selective agar. Single colonies were purified by plating, and five subsequent growth passages on agar containing the elevated antibiotic concentrations were performed prior to storage of the spontaneous antibiotic resistant mutant.

\section{Determination of miminum inhibitory concentrations}

MICs of antibiotics were determined using a broth microdilution technique in 96-well microtiter plates according to the British Society for Antimicrobial Chemotherapy (BSAC) guidelines [53]. Antibiotics were obtained from Sigma (amikacin, clavulanic acid potassium salt, erythromycin, gentamycin, levofloxacin, piperacillin sodium, rifampicin, sulfamethoxazole, tetracycline, tobramycin, trimethoprim), Fluka (azithromycin, ciprofloxacin) or MP Biomedicals (chloramphenicol). Meropenem was obtained from Chemos and ceftazidime from Sandoz. Clarofan from Aventis was used as a source of cefotaxime, Primaxin IV from Merck as a source of imipenem, and Azactam from Bristol-Myers Squibb for aztreonam. The non-antibiotic cationic drugs theophylline, chlorpromazine and perchlorperazine were all obtained from Sigma. For the spontaneous J2315 mutants, the antibiotic on which they were selected was not included in the MIC assays.

Microtiter plates containing $200 \mu \mathrm{l}$ of Iso-sensitest broth per well were inoculated with $5 \times 10^{5} \mathrm{CFU} / \mathrm{ml}$ of bacteria obtained by dilution of a fresh overnight culture. After incubation (routinely $24 \mathrm{~h}$, but up to $40 \mathrm{~h}$ for slow growing isolates) at $37^{\circ} \mathrm{C}$ (with rotary shaking at $200 \mathrm{rpm}$ ) growth was monitored spectrophotometrically $(630 \mathrm{~nm})$ using a microtiter plate reader (MRX-TC Revelation, Dynex Technologies, Worthing, UK). Wells with an O.D. $>0.1$ were scored as positive for growth. The BSAC guidelines were followed for determining breakpoint sensitivities [54]. To evaluate additive or synergistic antibiotic effects of two compounds in combination, a checkerboard microdilution assay with 1.5-fold dilution steps was used. The mean fractional inhibitory concentraction (FIC) index was calculated according to standard procedures. Synergy was defined as an FIC index of $\leq 0.5$, additivity or indifference was defined as an FIC index of $>0.5$ to 4 [55].

\section{Microarray analysis}

Bacteria were cultivated for the microarray experiments in $25 \mathrm{ml}$ Iso-sensitest medium held in $250 \mathrm{ml}$ flasks; each was inoculated with $5 \times 10^{8} \mathrm{CFU}$ and incubated at $37^{\circ} \mathrm{C}$ on a rotary shaker $(150 \mathrm{rpm})$. Antibiotics and 
chlorpromazine were added at sub-inhibitory concentrations at the time of inoculation (the concentrations are given in Table 2 and Figure 1). The concentrations were chosen because they resulted in a $20 \%$ reduction of growth rate, this ensuring the bacteria were affected by the antibiotics but not in a lethal way. In the case of spontaneous mutants, experiments were performed at two different antibiotic concentrations: the same concentrations as used for the wild type (which did not alter the growth rate of the mutants significantly), and a higher concentration, again chosen to reduce the growth rate of each mutant by $20 \%$. Growth was monitored spectrophotometrically and the bacteria harvested at an O.D. of 0.5 (approximately $5 \times 10^{8} \mathrm{CFU} / \mathrm{ml}$ ). Cultures were swiftly aliquoted into microcentrifuge tubes and snap-cooled in liquid nitrogen before centrifuging at $20.000 \times \mathrm{g}$ at $4^{\circ} \mathrm{C}$ for $1 \mathrm{~min}$. Pellets were immediately frozen at $-80^{\circ} \mathrm{C}$ and RNA was extracted within one week of harvest using the RiboPure Bacteria Kit (Ambion/ Applied Biosystems) including the optional DNase I treatment of the kit. LiCl precipitation (Ambion/Applied Biosystems) was used to concentrate the RNA and its quality was assessed with a Bioanalyzer using the RNA 6000 Nano kit (Agilent).

RNA was indirectly labelled with the CyScribe PostLabelling Kit (GE Healthcare), with the first strand cDNA generated using random nonamers and incorporating amino allyl-dUTPs, which were then chemically labelled in a second step to minimise any dye bias. $10 \mu \mathrm{g}$ of total RNA were used per labelling reaction and Spike-In controls (Agilent) were added to the labelling mix. B. cenocepacia genomic DNA was extracted as described [56] and labelled with the CyScribe Array CGH Genomic DNA Labeling System (GE Healthcare) at $1 \mu \mathrm{g}$ per labelling reaction. A reference design was used for the microarray experiments with $\mathrm{Cy} 3$ labelled reference RNA or genomic DNA run as the control channel for all experiments. All experiments were performed with three biological replicates, and compared to three biological replicates of a J2315 control grown on Iso-sensitest medium without any antibiotics.

A custom microarray for B. cenocepacia J2315 was used, [10] however, the design was updated with each probes printed four times in a randomised distribution using the Agilent SurePrint $4 \times 44 \mathrm{~K}$ microarray platform (design AMADID\#017397; ArrayExpress http://www.ebi. ac.uk/arrayexpress accession number A-MEXP-1613). Microarrays were hybridized according to the Two-Colour Microarray Based Gene Expression Analysis protocol (Agilent), except that it was adjusted for the use of cDNA by omitting the fragmentation step. Labelled experimental cDNA was used at $825 \mathrm{ng}$ per microarray and labelled control genomic DNA was used at 200 ng per microarray. Hybridization, washing and scanning was performed as described in the Two-colour Microarray protocol and the data analysed using GeneSpring GX version 7.3.1.

8740 probes (7251 coding sequences [CDS] and 1489 intergenic [IG]) specific to J2315 were evaluated as follows: (i) unreliable features were filtered out (features had to have a p-value $\leq 0.05$ in at least half of the samples to be used for analysis); (ii) a filter on 1.5-fold change in expression in the test condition compared to the control condition (wild type without antibiotics) was applied, and (iii) a one-way ANOVA was carried out on the resulting gene lists, using a Welch t-test with $5 \%$ false discovery rate (and without multiple testing correction). An initial cut-off of 2-fold change was used for global analysis of differential gene expression. To verify co-regulation of adjacently encoded genes, those within clusters, or those with known roles in antibiotic resistance, a more relaxed cut-off of 1.5fold change was used and reported if found to be statistically significant. The microarray raw data is accessible in ArrayExpress (accession numbers E-MEXP-2708, -2738 and -2747) and the complete gene expression dataset (including the statistical confidence data) is available as a supplementary data spreadsheet (Additional file 2).

\section{qPCR for validation of microarray results}

qPCR primers and annealing temperatures are listed in Additional file 1, Table S3. The correct size of amplification product and absence of unspecific product was confirmed by PCR on genomic DNA and subsequent agarose gel electrophoresis. RNA was extracted with the RiboPure Bacteria Kit (Ambion/Applied Biosystems) from newly generated biological replicates as follows: (i) one set mimicking the same culture conditions and concentrations of antibiotics used for microarray experiments; (ii) two sets of biological replicates where the culture conditions were modified and J2315 was grown on Iso-sensitest medium to O.D. ${ }_{600} 0.5$ without drugs, before adding higher but still sub-inhibitory concentrations of drugs (AMK $250 \mathrm{mg} / \mathrm{L}$, MEM $20 \mathrm{mg} / \mathrm{L}$, TMP-SMX 50 and $250 \mathrm{mg} / \mathrm{L}$, chlorpromazine $0.25 \mathrm{mM}$ ). This reduced the doubling time by 10 to $20 \%$, and then the control and test cultures were harvested after further growth to O.D.600 1.0. Extracted RNA was diluted to $150 \mathrm{ng} / \mu \mathrm{l}$ and treated for a second time with DNase (RQ1, Promega). cDNA was generated with the ImProm-II Reverse Transcription System (Promega) using 200 ng RNA per reaction. Real-time qPCR was performed as described in Drevinek et al. [10] using $250 \mathrm{ng}$ cDNA per reaction; non-amplification, non-template, and no reverse transcriptase controls were included in all assays. Multiple reference genes were evaluated as controls for qPCR (data not shown) and BCAM0918, encoding RpoD, selected as the most stably expressed control gene as it showed minimal changes in expression across all conditions used in this study. Fold changes were calculated according to the delta delta $\mathrm{C}_{\mathrm{T}}$ method. $\mathrm{qPCR}$ was also 
used for investigating expression of selected genes in different strains (J2315, K56-2 and J2315-M; see below) under the following conditions: LB medium with and without glucose $(20 \mathrm{mM})$, and with and without salicylate $(10 \mathrm{mM})$. Growth, RNA extraction and qPCR was performed exactly as described above.

\section{Genetic manipulation}

B. vietnamiensis $\mathrm{G} 4$ was used as an antibiotic susceptible complementation host for genes or gene clusters implicated in antibiotic resistance and with no close homologues in this strain. Genes were cloned into the arabinose inducible pMLBAD vector and introduced into $B$. vietnamiensis G4 by triparental mating [57]. The correct insert identity was confirmed by sequencing. Primer sequences for construction of the vectors are listed in Additional file 1 , Table S3. Selection after triparental mating was performed on tryptone soya agar containing $75 \mathrm{mg} / \mathrm{L}$ trimethoprim and $400 \mathrm{U} / \mathrm{ml}$ polymyxin. MIC tests were performed on two transformants of each gene and gene cluster tested and compared to B. vietnamensis $\mathrm{G} 4$ transformed with pMLBAD. The test medium was supplemented with arabinose at $0.5 \%$ final concentration, no trimethoprim selection was applied during the MIC tests. B. cenocepacia K56-2 was used for mutagenesis experiments and unmarked deletions were constructed using the yeast homing endonuclease I-SceI, as described by Flannagan et al. [58]. Transformation was performed by electroporation. Primer sequences for construction of pGPI derivatives are listed in Additional file 1, Table S3. All mutations were confirmed by PCR and subsequent phenotypic testing was carried out on two independently isolated mutants.

\section{Bioinformatic analysis}

Putative promoters and regulator binding sites were predicted by analysing the upstream region of upregulated genes with the motif discovery tool MEME [59]. The binding sites predicted by MEME were used for a search against genomes of other Burkholderia species using the MAST tool [60]. Signal peptides were predicted using SignalP 3.0 [61] and subcellular location of proteins was predicted with PSORT-B [62]. Homologues for genes across the genus Burkholderia were searched for by BLASTp [63] or the Burkholderia Genome Database [64].

\section{Additional material}

Additional file 1: Supplementary tables and figures. A single document containing the following supplementary material: (i) Table S1: Fold changes in B. cenocepacia gene expression determined by qPCR; (ii) Table S2: Strains and plasmids used in this study; (iii) Table S3: PCR primers used in this study; and (iv) Figure S1. Swimming motility of $B$. cenocepacia J2315 and the outbreak isolates.
Additional file 2: Summary of significant changes in $B$. cenocepacia J2315 gene expression observed for all the conditions tested. An Excel spreadsheet of all genes significantly altering their expression under the conditions examined is provided. Columns are provided for the systematic gene identifier (Gene ID) and its functional annotation in the $B$. cenocepacia genome [6], the fold gene expression change under the conditions examined (see Figure 1), and the statistical confidence pvalue associated with each gene expression change.

\section{Acknowledgements and funding}

We thank Pavel Drevinek for helpful discussion on the microarray analysis. This work was supported by a grant fro the US Cystic Fibrosis Therapeutics program (grant number MAHENT06V0) and UK Cystic Fibrosis Trust (grant PJ551).

\section{Author details}

'Organisms and Environment Division, Cardiff School of Biosciences, Cardiff University, Main Building, Park Place, Cardiff, Wales, CF10 3AT, UK. ' University of Toronto, Department of Medicine, Division of Respirology, 1 King's College Circle, 6263 Medical Sciences Building, Toronto, ON, M5S 1A8, Canada. ${ }^{3}$ University of Michigan Medical School, 1150 W. Medical Centre Drive, 8323 MRSB III, Box 0646, Ann Arbor, Michigan, MI 48109-646, USA.

\section{Authors' contributions}

AS and AM performed all the experimental work. EM conceived the study and both EM and AS participated in the design of experiments. ET and JJP provided resources and information for the outbreak strains examined. AS, JJP and EM wrote the paper, and all authors have read and approved the final manuscript.

\section{Competing interests}

The authors declare that they have no competing interests.

Received: 15 November 2010 Accepted: 22 July 2011

Published: 22 July 2011

\section{References}

1. Lipuma JJ: The changing microbial epidemiology in cystic fibrosis. Clin Microbiol Rev 2010, 23(2):299-323.

2. Isles A, Maclusky I, Corey M, Gold R, Prober C, Fleming P, Levison H: Pseudomonas cepacia infection in cystic fibrosis: an emerging problem. J Pediatr 1984, 104(2):206-210.

3. Govan JR, Brown PH, Maddison J, Doherty CJ, Nelson JW, Dodd M, Greening AP, Webb AK: Evidence for transmission of Pseudomonas cepacia by social contact in cystic fibrosis. Lancet 1993, 342(8862):15-19.

4. Mahenthiralingam E, Urban TA, Goldberg JB: The multifarious, multireplicon Burkholderia cepacia complex. Nat Rev Microbiol 2005, 3(2):144-156.

5. Mahenthiralingam E, Baldwin A, Dowson CG: Burkholderia cepacia complex bacteria: opportunistic pathogens with important natural biology. J App/ Microbiol 2008, 104(6):1539-1551.

6. Holden MTG, Seth-Smith HMB, Crossman LC, Sebaihia M, Bentley SD, Cerdeño-Tárraga AM, Thomson NR, Bason N, Quail MA, Shar S, et al: The genome of Burkholderia cenocepacia J2315, an epidemic pathogen of cystic fibrosis patients. J Bacteriol 2009, 91(1):261-277.

7. Drevinek P, Mahenthiralingam E: Burkholderia cenocepacia in cystic fibrosis: epidemiology and molecular mechanisms of virulence. Clin Microbiol Infec 2010, 16(7):821-830.

8. Aaron SD, Ferris W, Henry DA, Speert DP, Macdonald NE: Multiple combination bactericidal antibiotic testing for patients with cystic fibrosis infected with Burkholderia cepacia. Am J Respir Crit Care Med 2000, 161(4 Pt 1):1206-1212.

9. St Denis M, Ramotar K, Vandemheen K, Tullis E, Ferris W, Chan F, Lee C, Slinger R, Aaron SD: Infection with Burkholderia cepacia complex bacteria and pulmonary exacerbations of cystic fibrosis. Chest 2007, 131(4):1188-1196.

10. Drevinek P, Holden MTG, Ge Z, Jones AM, Ketchell I, Gill RT, Mahenthiralingam E: Gene expression changes linked to antimicrobial resistance, oxidative stress, iron depletion and retained motility are 
observed when Burkholderia cenocepacia grows in cystic fibrosis sputum. BMC Infect Dis 2008, 8:121.

11. O'Grady EP, Viteri DF, Malott RJ, Sokol PA: Reciprocal regulation by the CepIR and CcilR quorum sensing systems in Burkholderia cenocepacia. BMC Genomics 2009, 10:441.

12. Buroni S, Pasca MR, Flannagan RS, Bazzini S, Milano A, Bertani I, Venturi V, Valvano MA, Riccardi G: Assessment of three Resistance-Nodulation-Cell Division drug efflux transporters of Burkholderia cenocepacia in intrinsic antibiotic resistance. BMC Microbiol 2009, 9:200.

13. Rajyaguru JM, Muszynski MJ: Sensitization of Burkholderia cepacia to antibiotics by cationic drugs. J Antimicrob Chemother 1998, 41(2):277-280.

14. Chernish RN, Aaron SD: Approach to resistant gram-negative bacterial pulmonary infections in patients with cystic fibrosis. Curr Opin Pulm Med 2003, 9(6):509-515.

15. Mclntyre K, Muller M, Ota J, Stephenson AL, Tullis E: Epidemic of Burkholderia cenocepacia ET12 in the Toronto Adult Cystic Fibrosis clinic: Lessons learned. Pediatric Pulmonology 2009.

16. Rodríquez-Rojas A, Mena A, Martín S, Borrell N, Oliver A, Blázquez J: Inactivation of the hmgA gene of Pseudomonas aeruginosa leads to pyomelanin hyperproduction, stress resistance and increased persistence in chronic lung infection. Microbiology 2009, 155(4):1050-1057.

17. Levin BR, Rozen DE: Non-inherited antibiotic resistance. Nat Rev Microbiol 2006, 4(7):556-562

18. Mahenthiralingam E, Campbell ME, Speert DP: Nonmotility and phagocytic resistance of Pseudomonas aeruginosa isolates from chronically colonized patients with cystic fibrosis. Infect/mmun 1994, 62(2):596-605.

19. Barth AL, Pitt TL: Auxotrophy of Burkholderia (Pseudomonas) cepacia from cystic fibrosis patients. J Clin Microbio 1995, 33(8):2192-2194.

20. Keith KE, Killip L, He P, Moran GR, Valvano MA: Burkholderia cenocepacia C5424 produces a pigment with antioxidant properties using a homogentisate intermediate. J Bacterio/ 2007, 189(24):9057-9065.

21. Larsen GY, Stull TL, Burns JL: Marked phenotypic variability in Pseudomonas cepacia isolated from a patient with cystic fibrosis. J Clin Microbiol 1993, 31(4):788-792

22. Peeters E, Sass A, Mahenthiralingam E, Nelis H, Coenye T: Transcriptional response of Burkholderia cenocepacia J2315 sessile cells to treatments with high doses of hydrogen peroxide and sodium hypochlorite. BMC Genomics 2010, 11:90.

23. Mingeot-Leclercq MP, Glupczynski Y, Tulkens PM: Aminoglycosides: Activity and resistance. Antimicrobial Agents Chemother 1999, 43(4):727-737.

24. Menard A, de los Santos P, Graindorge A, Cournoyer B: Architecture of Burkholderia cepacia complex 70 ogene family: Evidence of alternative primary and clade-specific factors, and genomic instability. BMC Genomics 2007, 8:308.

25. Kazmierczak MJ, Wiedmann M, Boor KJ: Alternative sigma factors and their roles in bacterial virulence. Microbiol Mol Biol Reviews 2005, 69(4):527-543.

26. Kobayashi N, Nishino K, Yamaguchi A: Novel macrolide-specific ABC-type efflux transporter in Escherichia coli. J Bacteriol 2001, 183(19):5639-5644.

27. Trépanier S, Prince A, Huletsky A: Characterization of the penA and penR genes of Burkholderia cepacia 249 which encode the chromosomal class A penicillinase and its LysR-type transcriptional regulator. Antimicrobial Agents Chemother 1997, 41(11):2399-2405.

28. Yigit H, Queenan AM, Anderson GJ, Domenech-Sanchez A, Biddle JW, Steward CD, Alberti S, Bush K, Tenover FC: Novel carbapenem-hydrolyzing $\beta$-lactamase, KPC-1, from a carbapenem-resistant strain of Klebsiella pneumoniae. Antimicrobial Agents Chemother 2001, 45(4):1151-1161.

29. Poirel L, Rodriguez-Martinez JM, Plésiat $P$, Nordmann P: Naturally occurring class a B-lactamases from the Burkholderia cepacia complex. Antimicrobial Agents Chemother 2009, 53(3):876-882.

30. Kim JY, Jung HI, An YJ, Lee JH, Kim SJ, Jeong SH, Lee KJ, Suh PG, Lee HS, Lee $\mathrm{SH}$, et al: Structural basis for the extended substrate spectrum of CMY-10, a plasmid-encoded class C $\beta$-lactamase. Mol Microbiol 2006, 60(4):907-916.

31. Olivera ER, Minambres B, García B, Muñiz C, Moreno MA, Ferrández A, Díaz E, García JL, Luengo JM: Molecular characterization of the phenylacetic acid eatabolic pathway in Pseudomonas putida U: The phenylacetyl-CoA catabolon. Proc Natl Acad Sci USA 1998, 95(11):6419-6424

32. Luengo JM, García JL, Olivera ER: The phenylacetyl-CoA catabolon: A complex catabolic unit with broad biotechnological applications. $\mathrm{Mol}$ Microbiol 2001, 39(6):1434-1442.
33. Hamlin JN, Bloodworth RA, Cardona ST: Regulation of phenylacetic acid degradation genes of Burkholderia cenocepacia K56-2. BMC Microbiol 2009, 9:222

34. Proctor RA, von Eiff C, Kahl BC, Becker K, McNamara P, Herrmann M, Peters G: Small colony variants: a pathogenic form of bacteria that facilitates persistent and recurrent infections. Nat Rev Microbiol 2006, 4(4):295-305.

35. Chain PS, Denef VJ, Konstantinidis KT, Vergez LM, Agullo L, Reyes VL, Hauser L, Cordova M, Gomez L, Gonzalez M, et al: Burkholderia xenovorans LB400 harbors a multi-replicon, 9.73-Mbp genome shaped for versatility. Proc Natl Acad Sci USA 2006, 103(42):15280-15287.

36. Law RJ, Hamlin JNR, Sivro A, McCorrister SJ, Cardama GA, Cardona ST: A functional phenylacetic acid catabolic pathway is required for full pathogenicity of Burkholderia cenocepacia in the Caenorhabditis elegans host model. J Bacteriol 2008, 190(21):7209-7218.

37. Huber B, Feldmann F, Köthe M, Vandamme P, Wopperer J, Riedel K, Eberl L: Identification of a novel virulence factor in Burkholderia cenocepacia H111 required for efficient slow killing of Caenorhabditis elegans. Infect Immun 2004, 72(12):7220-7230.

38. Lewenza S, Conway B, Greenberg EP, Sokol PA: Quorum sensing in Burkholderia cepacia: Identification of the LuxRI homologs CepRI. J Bacteriol 1999, 181(3):748-756.

39. Nair BM, Joachimiak LA, Chattopadhyay S, Montano I, Burns JL: Conservation of a novel protein associated with an antibiotic efflux operon in Burkholderia cenocepacia. FEMS Microbiol Letts 2005, 245(2):337-344.

40. Poole K: Efflux-mediated multiresistance in Gram-negative bacteria. Clin Microbiol Infect 2004, 10(1):12-26.

41. Fraud S, Campigotto AJ, Chen Z, Poole K: MexCD-OprJ multidrug efflux system of Pseudomonas aeruginosa: Involvement in chlorhexidine resistance and induction by membrane-damaging agents dependent upon the AlgU stress response sigma factor. Antimicrobial Agents Chemother 2008, 52(12):4478-4482.

42. Kannenberg EL, Poralla K: Hopanoid biosynthesis and function in bacteria. Naturwissenschaften 1999, 86(4):168-176.

43. Feldman M, Bryan R, Rajan S, Scheffler L, Brunnert $S$, Tang $H$, Prince A: Role of flagella in pathogenesis of Pseudomonas aeruginosa pulmonary infection. Infect Immun 1998, 66(1):43-51.

44. Wolfgang MC, Jyot J, Goodman AL, Ramphal R, Lory S: Pseudomonas aeruginosa regulates flagellin expression as part of a global response to airway fluid from cystic fibrosis patients. Proc Natl Acad Sci USA 2004, 101(17):6664-6668.

45. Allikmets R, Gerrard B, Court D, Dean M: Cloning and organization of the abc and mdl genes of Escherichia coli: relationship to eukaryotic multidrug resistance. Gene 1993, 136(1-2):231-236.

46. Hunt TA, Kooi C, Sokol PA, Valvano MA: Identification of Burkholderia cenocepacia genes required for bacterial survival in vivo. Infect Immun 2004, 72(7):4010-4022.

47. Kohanski MA, Dwyer DJ, Hayete B, Lawrence CA, Collins JJ: A common mechanism of cellular death induced by bactericidal antibiotics. Cell 2007, 130(5):797-810

48. Drevinek P, Baldwin A, Lindenburg L, Joshi LT, Marchbank A, Vosahlikova S, Dowson CG, Mahenthiralingam E: Oxidative stress of Burkholderia cenocepacia induces insertion sequence-mediated genomic rearrangements that interfere with macrorestriction-based genotyping. J Clin Microbiol 2010, 48(1):34-40.

49. Moore RA, Deshazer D, Reckseidler S, Weissman A, Woods DE: Effluxmediated aminoglycoside and macrolide resistance in Burkholderia pseudomallei. Antimicrobial Agents Chemother 1999, 43(3):465-470.

50. Chan YY, Tan TMC, Ong YM, Chua KL: BpeAB-OprB, a Multidrug Efflux Pump in Burkholderia pseudomallei. Antimicrobial Agents Chemother 2004, 48(4):1128-1135.

51. Hareland WA, Crawford RL, Chapman PJ, Dagley S: Metabolic function and properties of 4-hydroxyphenylacetic acid 1-hydroxylase from Pseudomonas acidovorans. J Bacteriol 1975, 121(1):272-285.

52. Baldwin A, Mahenthiralingam E, Thickett KM, Honeybourne D, Maiden MCJ, Govan JR, Speert DP, Lipuma JJ, Vandamme P, Dowson CG: Multilocus sequence typing scheme that provides both species and strain differentiation for the Burkholderia cepacia complex. J Clin Microbiol 2005, 43(9):4665-4673. 
53. Andrews JM: Determination of minimum inhibitory concentrations. J Antimicrobial Chemother 2001, 48(SUPPL 1):5-16.

54. MacGowan AP, Wise R: Establishing MIC breakpoints and the interpretation of in vitro susceptibility tests. $J$ Antimicrobial Chemother 2001, 48(SUPPL 1):17-28.

55. Den Hollander JG, Mouton JW, Verbrugh HA: Use of pharmacodynamic parameters to predict efficacy of combination therapy by using fractional inhibitory concentration kinetics. Antimicrobial Agents Chemothery 1998, 42(4):744-748.

56. Mahenthiralingam E, Campbell ME, Foster J, Lam JS, Speert DP: Random amplified polymorphic DNA typing of Pseudomonas aeruginosa isolates recovered from patients with cystic fibrosis. I Clinical Microbiol 1996, 34(5):1129-1135.

57. Lefebre MD, Valvano MA: Construction and evaluation of plasmid vectors optimized for constitutive and regulated gene expression in Burkholderia cepacia complex isolates. Appl Environ Microbiol 2002, 68(12):5956-5964.

58. Flannagan RS, Linn T, Valvano MA: A system for the construction of targeted unmarked gene deletions in the genus Burkholderia. Environ Microbiol 2008, 10(6):1652-1660

59. Bailey TL, Elkan C: Fitting a mixture model by expectation maximization to discover motifs in biopolymers. Proceedings/International Conference on Intelligent Systems for Molecular Biology; ISMB International Conference on Intelligent Systems for Molecular Biology 1994, 2:28-36.

60. Bailey TL, Gribskov M: Combining evidence using p-values: Application to sequence homology searches. Bioinformatics 1998, 14(1):48-54.

61. Bendtsen JD, Nielsen H, Von Heijne G, Brunak S: Improved prediction of signal peptides: SignalP 3.0. J Mol Biol 2004, 340(4):783-795.

62. Gardy JL, Laird MR, Chen F, Rey S, Walsh CJ, Ester M, Brinkman FSL: PSORTb v.2.0: Expanded prediction of bacterial protein subcellular localization and insights gained from comparative proteome analysis. Bioinformatics 2005, 21(5):617-623.

63. Altschul SF, Madden TL, SchÃuffer AA, Zhang J, Zhang Z, Miller W, Lipman DJ: Gapped BLAST and PSI-BLAST: A new generation of protein database search programs. Nucleic Acids Research 1997, 25(17):3389-3402.

64. Winsor GL, Khaira B, Van Rossum T, Lo R, Whiteside MD, Brinkman FSL: The Burkholderia Genome Database: Facilitating flexible queries and comparative analyses. Bioinformatics 2008, 24(23):2803-2804.

doi:10.1186/1471-2164-12-373

Cite this article as: Sass et al: Spontaneous and evolutionary changes in the antibiotic resistance of Burkholderia cenocepacia observed by global gene expression analysis. BMC Genomics 2011 12:373.

\section{Submit your next manuscript to BioMed Central and take full advantage of:}

- Convenient online submission

- Thorough peer review

- No space constraints or color figure charges

- Immediate publication on acceptance

- Inclusion in PubMed, CAS, Scopus and Google Scholar

- Research which is freely available for redistribution

Submit your manuscript at www.biomedcentral.com/submit
Biomed Central 